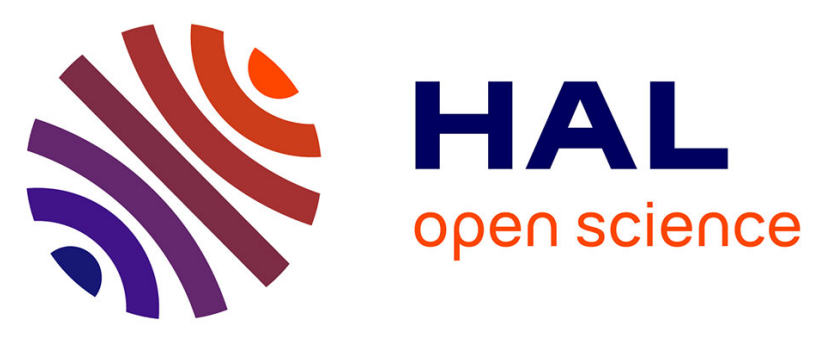

\title{
Photochemistry of CF3Cl: Quenching of Charged Fragments Is Caused by Nonadiabatic Effects
}

Vanessa C de Medeiros, Railton B de Andrade, Gessenildo P. Rodrigues, Glauco F Bauerfeldt, Elizete Ventura, Mario Barbatti, Silmar A Do Monte

\section{- To cite this version:}

Vanessa C de Medeiros, Railton B de Andrade, Gessenildo P. Rodrigues, Glauco F Bauerfeldt, Elizete Ventura, et al.. Photochemistry of CF3Cl: Quenching of Charged Fragments Is Caused by Nonadiabatic Effects. Journal of Chemical Theory and Computation, 2018, 14 (9), pp.4844-4855. 10.1021/acs.jctc.8b00457 . hal-01965454

\section{HAL Id: hal-01965454 \\ https://hal-amu.archives-ouvertes.fr/hal-01965454}

Submitted on 26 Dec 2018

HAL is a multi-disciplinary open access archive for the deposit and dissemination of scientific research documents, whether they are published or not. The documents may come from teaching and research institutions in France or abroad, or from public or private research centers.
L'archive ouverte pluridisciplinaire HAL, est destinée au dépôt et à la diffusion de documents scientifiques de niveau recherche, publiés ou non, émanant des établissements d'enseignement et de recherche français ou étrangers, des laboratoires publics ou privés. 


\title{
Photochemistry of $\mathrm{CF}_{3} \mathrm{Cl}$ : Quenching of Charged Fragments is Caused by Nonadiabatic Effects
}

\author{
Vanessa C. de Medeiros ${ }^{\dagger}$, Railton B. de Andrade ${ }^{\dagger}$, Gessenildo P. Rodrigues ${ }^{\dagger}$, Glauco F. \\ Bauerfeldt ${ }^{\dagger \dagger}$, Elizete Ventura ${ }^{\dagger}$, Mario Barbatti ${ }^{\ddagger *}$, and Silmar A. do Monte ${ }^{\dagger *}$
}

†Departamento de Química, CCEN, Universidade Federal da Paraíba, João Pessoa, PB, 58.059-900, Brazil

†Departamento de Química, Instituto de Ciências Exatas, UFRRJ, Pavilhão Roberto Alvahydo (PQ), sala 44. km 7, Rodovia Br 465, Seropédica, RJ 23890-000, Brazil

${ }^{*}$ Aix Marseille Univ, CNRS, ICR, Marseille, France

\begin{abstract}
For the first time, high-level multireference electronic structure calculations have been performed to study the photochemistry of $\mathrm{CF}_{3} \mathrm{Cl}$, allowing a comprehensive interpretation and assignment of experimental data concerning fluorescence, ion-pair formation, and generation of $\mathrm{CF}_{3}$ fragments in several electronic states. All studied dissociation channels correlate either with $\mathrm{Cl}_{\text {or }} \mathrm{Cl}^{-}$in the ground state. On the other hand, $\mathrm{CF}_{3}$ fragment can be generated either in the ground or excited state. A rationalization for the nonadiabatic relaxation of $\mathrm{CF}_{3} \mathrm{Cl}$, including the formation of an $(\mathrm{n} 4 \mathrm{~s})$ stable state and internal conversion at multiple-state intersections, has been provided. Our results explain the anomalous quenching of charged fragment after low-energy excitation experimentally observed by separate groups. We show that the $\mathrm{CF}_{3}{ }^{+} \ldots \mathrm{Cl}^{-}$ion pair undergoes an internal conversion to the ground state, producing neutral $\mathrm{CF}_{3}$ and $\mathrm{Cl}$ fragments. The results also allow understanding why $\mathrm{CF}_{3} \mathrm{Cl}$ is usually a non-emitting species and how $\mathrm{UV}$ emission could be induced.
\end{abstract}




\section{INTRODUCTION}

$\mathrm{CF}_{3} \mathrm{Cl}$ (Chlorotrifluoromethane, $\mathrm{CFC}-13$ ) has been used as a refrigerant for decades, and it is clear that the remaining content of $\mathrm{CF}_{3} \mathrm{Cl}$ in the atmosphere has come from anthropogenic sources. ${ }^{1}$ Due to its ozone depleting and global warming characteristics, the production and use of $\mathrm{CF}_{3} \mathrm{Cl}$ have been phased out under the Montreal Protocol. ${ }^{2}$ However, its relatively long atmospheric lifetime $\left(\sim 640\right.$ years $\left.^{3}\right)$ still makes it a source of great concern. Moreover, a recent report of an unexpected increase of the atmospheric CFC concentration in the last years ${ }^{4}$ has raised concerns on the possible breach of the Montreal Protocol.

Given that $\mathrm{CF}_{3} \mathrm{Cl}$ harmful effect to the ozone layer is related to $\mathrm{Cl}$ radicals, ${ }^{5-7}$ its photolysis has been the subject of intense research for decades. ${ }^{8-11} \mathrm{An}$ anomalous feature in this photolysis was reported long ago by Schenk et al. ${ }^{12}$ and more recently confirmed by Simpson et al. ${ }^{13}$ Both groups showed that the $\mathrm{Cl}^{-}$anion formation only occurs for energies over $16.1 \mathrm{eV}$, despite the fact that the calculated enthalpy for the $\mathrm{CF}_{3} \mathrm{Cl} \rightarrow \mathrm{CF}_{3}{ }^{+}+\mathrm{Cl}^{-}$ionpair reaction is only $9.2 \mathrm{eV}$. Thus, although this reaction channel is energetically accessible, the experimental data shows that, at low energy excitations, only neutral fragments are formed. As discussed by Simpson et al. ${ }^{13}$ this anomalous behavior - whose molecular basis has not been explained so far - is not exclusive of $\mathrm{CF}_{3} \mathrm{Cl}$ and is also observed in $\mathrm{CF}_{3} \mathrm{Br}$ and $\mathrm{CF}_{3} \mathrm{I}$. In these species, after excitation below the ionization threshold, $\mathrm{Br}^{-}$signal is also absent and $\mathrm{I}^{-}$signal is much weaker than expected.

Another relevant spectroscopic feature of $\mathrm{CF}_{3} \mathrm{Cl}$ is its fluorescent signature. It has been experimentally determined that $\mathrm{CF}_{3} \mathrm{Cl}$ emission has an onset at about $10 \mathrm{eV},{ }^{14}$ yielding two broad bands, one in the UV and another in the visible. ${ }^{8}$ Nonetheless, neither of these bands are due to $\mathrm{CF}_{3} \mathrm{Cl}$ itself, but from its $\mathrm{CF}_{3} *$ fragments.

In this paper, we use uncontracted multireference configuration interactions with singles and doubles plus size-extensivity corrections (MR-CISD+Q) based on extended triple- $\zeta$ basis sets to map the excited states of $\mathrm{CF}_{3} \mathrm{Cl}$, including its valence and Rydberg states. With a focus on the nonadiabatic relaxation pathways along the $\mathrm{C}-\mathrm{Cl}$ fragmentation, dissociation into the five lowest dissociation channels is discussed. This analysis has unveiled the molecular mechanism responsible for the anomalous quenching of the charged- 
fragments. Among several excited- and ground-state reaction channels, we show that when the lowest-energy $\mathrm{CF}_{3}{ }^{+} \ldots \mathrm{Cl}^{-}$ion-pair state is formed, it couples to the ground state, nonadiabatically quenching the production of charged fragments. This sequence of nonadiabatic events helps explain not only the quenching of $\mathrm{Cl}^{-}$but also allows a full rationalization of the intrinsic darkness of $\mathrm{CF}_{3} \mathrm{Cl}$. In addition, we show how UV emission from the bound species could be triggered.

As some of us have discussed in ref. ${ }^{15}$, the computational chemistry of halogenated compounds is still a significant challenge, with popular methods often delivering low accuracy results. This work is part of a more general research program to investigate such class of compounds with multireference highly correlated methods. ${ }^{16-19}$ Working with such high-level methods does not fully solve the accuracy problem, but it has allowed us to do an in-depth analysis of the potential energy surfaces of these compounds, revealing the diabatic transformations along reaction pathways. This is once more achieved in this work, where the picture derived for $\mathrm{CF}_{3} \mathrm{Cl}$ goes beyond this single molecule and shed light on the photodissociation patterns of other halogenfluorocarbons.

\section{COMPUTATIONAL DETAILS}

$\mathrm{C}_{\mathrm{s}}$ symmetry has been used in the calculations of most of the stationary points, except the conical intersection, whose calculation has been performed without symmetry restriction. The symmetry plane corresponds to the xy plane. The $\mathrm{Cl}$ atom $3 \mathrm{p}$ lone pair along the $\mathrm{C}-\mathrm{Cl}$ axis is designated as $3 p_{\sigma}$, and its interaction with the $2 p_{\sigma}(C)$ orbital of the $\mathrm{CF}_{3}$ moiety yields the bonding and anti-bonding $\sigma$ and $\sigma^{*}$ orbitals. The degenerate lone pair orbitals $\left(3 p_{\mathrm{y}}, 3 \mathrm{p}_{\mathrm{z}}\right)$ are referred as $n_{e}$. The $2 p_{\sigma}, \sigma, \sigma^{*}$, and $n_{e}$ valence orbitals have been considered in the present study. Valence and Rydberg orbitals of $\mathrm{CF}_{3}$ have also been taken into account. The valence orbital is mainly formed by an equal combination of fluorine lone pairs $n_{F}\left(A_{1}\right.$ in the $C_{3 v}$ point group). The Rydberg orbitals are the $n s, n p_{\sigma}$, and $n p_{e}$, with $n=3$ or 4 depending on whether they are localized on the $\mathrm{C}$ or $\mathrm{Cl}$ atom. ${ }^{18-19}$

For the multiconfigurational self-consistent field (MCSCF) calculations, a valence complete active space (CAS) has been chosen to comprise 8 electrons (four from the $\mathrm{n}_{\mathrm{e}}$ 
orbitals, two from the $\sigma$ bond, and two from the $\mathrm{n}_{\mathrm{F}}$ orbital). The $\mathrm{n}_{\mathrm{F}}$ orbital has been included based on the study of Washida et al., ${ }^{9}$ which reported a valence state interspersed between some Rydberg states. Another important feature is that its inclusion leads to a sufficiently flexible occupied space at a manageable computational cost and, at the same time, keeps the correct shape of the high-lying $3 \mathrm{p}(\mathrm{C})$ Rydberg orbitals upon dissociation. The $\sigma^{*}$ orbital has also been included in the CAS, while the four Rydberg orbitals (ns, $n p_{\sigma}$, and $n p_{e}$ ) have been included in the auxiliary (AUX) space and only single CAS $\rightarrow$ AUX excitations were allowed. As the actual symmetry along the potential energy curves is $\mathrm{C}_{3 \mathrm{v}}$ and the calculations have been performed using $\mathrm{C}_{\mathrm{s}}$ symmetry, one needs to compute the average energies using the correct pairs of $\mathrm{A}^{\prime}$ and $\mathrm{A}^{\prime \prime}$ roots to obtain the energies of the E states. Eleven singlet states (at the $\mathrm{C}_{3 \mathrm{v}}$ symmetry) with equal weights have been included in the state-averaged MCSCF calculations. At the $\mathrm{C}_{\mathrm{s}}$ group, this set of states corresponds to a total of $10 \mathrm{~A}^{\prime}$ and $6 \mathrm{~A}^{\prime \prime}$ roots. At the equilibrium geometry, the correspondence is the same as that obtained for the $\mathrm{CH}_{3} \mathrm{Cl}$ molecule, ${ }^{18}$ that is, $1^{1} \mathrm{~A}_{1}-1^{1} \mathrm{~A}^{\prime} ; 1^{1} \mathrm{E}-\left(2^{1} \mathrm{~A}^{\prime}+1{ }^{1} \mathrm{~A}^{\prime \prime}\right) ; 2^{1} \mathrm{E}-\left(3{ }^{1} \mathrm{~A}^{\prime}+2{ }^{1} \mathrm{~A}^{\prime \prime}\right) ; 2^{1} \mathrm{~A}_{1}-5{ }^{1} \mathrm{~A}^{\prime} ; 3^{1} \mathrm{E}$ $-\left(4^{1} \mathrm{~A}^{\prime}+3{ }^{1} \mathrm{~A}^{\prime \prime}\right) ; 1^{1} \mathrm{~A}_{2}-4{ }^{1} \mathrm{~A}^{\prime \prime} ; 4^{1} \mathrm{E}-\left(6{ }^{1} \mathrm{~A}^{\prime}+5^{1} \mathrm{~A}^{\prime \prime}\right) ; 3^{1} \mathrm{~A}_{1}-7{ }^{1} \mathrm{~A}^{\prime} ; 4^{1} \mathrm{~A}_{1}-8^{1} \mathrm{~A}^{\prime} ; 5^{1} \mathrm{E}-\left(9^{1} \mathrm{~A}^{\prime}\right.$ $\left.+6{ }^{1} \mathrm{~A}^{\prime \prime}\right) ; 5^{1} \mathrm{~A}_{1}-10^{1} \mathrm{~A}^{\prime}$.

To generate the geometries to be used for the potential energy curves, a ground-staterelaxed scan along the $\mathrm{C}-\mathrm{Cl}$ coordinate has been performed at the unconstrained multireference configuration interaction with singles and double (MR-CISD) level, employing the valence space at both MCSCF and MR-CISD levels (see Table 1).

Table 1. Active and reference spaces used for the species studied in this manuscript. When it is the case, only single RAS $\rightarrow$ CAS and CAS $\rightarrow$ AUX excitations have been employed.

\begin{tabular}{|c|c|c|c|c|c|c|}
\hline \multirow[b]{2}{*}{$\mathrm{CF}_{3} \mathrm{Cl}$} & \multicolumn{3}{|c|}{ MCSCF } & \multicolumn{3}{|c|}{ MR-CISD } \\
\hline & RAS & CAS & AUX & RAS & CAS & AUX \\
\hline valence & ---- & $\mathrm{n}_{\mathrm{e}}, \sigma, \sigma^{*}$ & ---- & ---- & $\mathrm{n}_{\mathrm{e}}, \sigma, \sigma^{*}$ & --- \\
\hline ref1 & $\mathrm{n}_{\mathrm{F}}$ & $\mathrm{n}_{\mathrm{e}}, \sigma, \sigma^{*}$ & $\mathrm{~ns}, \mathrm{np}_{\sigma}, \mathrm{np}_{\mathrm{e}}$ & $\mathrm{n}_{\mathrm{F}}$ & $\mathrm{n}_{\mathrm{e}}, \sigma, \sigma^{*}$ & $\mathrm{~ns}, \mathrm{np}_{\sigma}, \mathrm{np}_{\mathrm{e}}$ \\
\hline ref2 & ---- & $\mathrm{n}_{\mathrm{F}}, \mathrm{n}_{\mathrm{e}}, \sigma, \sigma^{*}$ & $4 \mathrm{~s}(\mathrm{Cl})$ & ---- & $\mathrm{n}_{\mathrm{e}}, \sigma, \sigma^{*}$ & $4 \mathrm{~s}(\mathrm{Cl})$ \\
\hline ref3 & ---- & $\mathrm{n}_{\mathrm{F}}, \mathrm{n}_{\mathrm{e}}, \mathrm{n}_{\sigma}, 2 \mathrm{p}_{\sigma}$ & $\mathrm{ns}, \mathrm{np} \mathrm{p}_{\sigma}, \mathrm{np_{ \textrm {e } }}$ & ---- & $\mathrm{n}_{\mathrm{F}}, \mathrm{n}_{\mathrm{e}}, \mathrm{n}_{\sigma}, 2 \mathrm{p}_{\sigma}$ & $\mathrm{ns}, \mathrm{np}_{\sigma}, \mathrm{np}_{\mathrm{e}}$ \\
\hline $\mathrm{CF}_{3}$ & ---- & inner $^{a}+2 \mathrm{p}_{\sigma}(\mathrm{C})$ & $3 \mathrm{~s}, 3 \mathrm{p}$ & ---- & $2 \mathrm{p}_{\sigma}(\mathrm{C})$ & $3 \mathrm{~s}, 3 \mathrm{p}$ \\
\hline
\end{tabular}

${ }^{a}$ Except the four 1s orbitals of $\mathrm{C}$ and $\mathrm{F}$, which are in the doubly occupied space. 
In the case of the MR-CISD calculations, single-point calculations using the refl space (see Table 1) have been performed at the geometries obtained from a relaxed scan obtained with the valence space. The total CSF space is formed through single and double excitations from the active and doubly occupied orbitals into all virtual orbitals. Previous results ${ }^{19-20}$ shows that a frozen-core space formed by the $\mathrm{K}$ shell or by the $\mathrm{K}+\mathrm{L}$ shells of the $\mathrm{Cl}$ atom (both along with the $\mathrm{K}$ shell of the $\mathrm{C}$ atom) yields virtually the same results. Therefore, the second option has been chosen at the MR-CISD level. Davidson correction $(+Q)^{21-22}$ has been used to account for the size-extensivity. The d-aug-cc-pVTZ basis set for $\mathrm{C}$ and the aug-cc-pVTZ basis sets for $\mathrm{F}$ and $\mathrm{Cl}$ atoms ${ }^{23-26}$ have been used. This basis set combination will be referred as $\mathrm{B} 1$ throughout the paper.

The valence space has also been used for the geometry optimization of the ion-pair state and its nearby conical intersection between the $2^{1} \mathrm{~A}_{1}$ and $1{ }^{1} \mathrm{~A}_{1}$ states. Although localization of the Rydberg orbitals on the $\mathrm{Cl}$ or $\mathrm{C}$ atoms depends on the $\mathrm{C}-\mathrm{Cl}$ distance, preliminary tests at the MCSCF level indicate that the B1 basis set is flexible enough to handle both situations. Besides, these tests also indicate that localization and the main characteristics of the Rydberg orbitals are the same, no matter whether one uses the B1, B2 $=$ aug-cc-pVTZ $(\mathrm{C}, \mathrm{F}) / \mathrm{d}$-aug-cc-pVTZ $(\mathrm{Cl})$, or B3 = aug-cc-pVTZ $(\mathrm{F}) / \mathrm{d}$-aug-cc-pVTZ $(\mathrm{C}, \mathrm{Cl})$ basis set. Additionally, no significant variations have been observed for the results obtained with these three basis sets (at both MCSCF and MR-CISD levels), for the vertically excited states. Therefore, the B1 basis set has been chosen, except for geometry optimization of the conical intersection, for which the aug-cc-pVTZ basis set has been used. Cartesian coordinates for stationary structures and conical intersection are given in the Supporting Information.

The supermolecule approach for a $\mathrm{CF}_{3}-\mathrm{Cl}$ distance of $50 \AA$ has been used to perform single-point calculations with the B1 basis set to obtain the dissociation limits. For the ionpair channel, the residual Coulomb energy between the charged species $(0.29 \mathrm{eV}$ at $50 \AA)$ was further discounted from the potential energy of the supermolecule.

Additional full geometry optimizations have been performed for the for the $\mathrm{n}_{\mathrm{e}} 4 \mathrm{~s}(\mathrm{Cl})$ Rydberg state (which corresponds to the $2^{1} \mathrm{E}$ state near the ground state minimum), and for some higher Rydberg states, these latter at the MR-CIS level. For the $n_{e} 4 s$ Rydberg state, the 
ref2 space has been used (see Table 1). For the geometry optimizations of the ground state, conical intersection and the ion pair, the valence space has been used at both computational levels. These choices for the orbitals schemes are based on the relatively large energy gap between the studied states and the next one. For the $n_{e} 4 s$, ground, and ionic states, three, two, and three states (in the $\mathrm{C}_{3 \mathrm{v}}$ notation) have been averaged at the MCSCF level, respectively. In the case of geometry optimization of the higher Rydberg states, the ref 3 space has been used.

Different schemes have been used for the $\mathrm{CF}_{3}$ and $\mathrm{CF}_{3}{ }^{+}$fragments. At the MCSCF level, the 1 s orbitals of $\mathrm{C}$ and $\mathrm{F}$ are maintained in the doubly-occupied space. For the neutral fragment, all valence orbitals previously occupied at the restricted open-shell Hartree-Fock (ROHF) level are in the CAS space (that is, all doubly occupied + the singly occupied $2 \mathrm{p}_{\sigma}$ (C) orbital). The four $3 \mathrm{~s}$ and $3 \mathrm{p}$ Rydberg orbitals are in the AUX space, and only single CAS $\rightarrow$ AUX excitations are allowed. For the $\mathrm{CF}_{3}{ }^{+}$fragment, the MCSCF calculation coincides with a closed-shell SCF calculation, that is, there are no active orbitals.

At the MR-CISD level, the 1s orbitals of $\mathrm{C}$ and $\mathrm{F}$ are in the frozen-core space for both fragments. For $\mathrm{CF}_{3}$, the valence orbitals previously doubly occupied at the ROHF level are maintained in the doubly-occupied space at the MR-CISD level, while only the $2 \mathrm{p}_{\sigma}(\mathrm{C})$ orbital is in the CAS space. As before, the four Rydberg orbitals are in the AUX space, and only single $2 \mathrm{p}_{\sigma}(\mathrm{C}) \rightarrow$ AUX excitations are included while generating the reference configurations. For the $\mathrm{CF}_{3}{ }^{+}$fragment, the previously doubly-occupied orbitals at the restricted closed-shell Hartree-Fock (RHF) level are in the doubly occupied space at the MRCISD level. As the $2 p_{\sigma}(C)$ orbital is empty in this case, there is no CAS space (for the sake of consistency with the neutral fragment) and, consequently, no AUX space. Therefore, for the cation, the CI expansion is that of a single-reference CISD wavefunction. For this system, such scheme is essentially used for obtaining the zero-point energy (ZPE) and the optimized geometry of $\mathrm{CF}_{3}{ }^{+}$, and this geometry is used in the calculation of the dissociation limit for the ionic channel (section 3.6). The vibrational frequencies and the geometrical parameters are in good agreement with literature data. 
All geometry optimizations at the MR-CISD level have been performed through analytical gradient techniques, ${ }^{27-30}$ also available for optimization at the crossing seam, which is based on analytical nonadiabatic coupling vectors. ${ }^{31-32}$

To improve the vertical excitation energy of the no* state, and multi-reference average quadratic coupled cluster (MR-AQCC) $)^{33-34}$ calculations have also been performed with refl (see Table 1). As usual, intruder states showed up. They consist of additional CSFs (not included in the reference space) with reasonably large weights $(>1 \%)$. Thus, to achieve proper convergence these individual CSFs (up to four) have been added to refl. All MRCISD and MR-AQCC calculations have been performed with the interactive space restriction. $^{35}$

All calculations have been performed with the COLUMBUS program system. ${ }^{36-39}$ Modules taken from the DALTON program ${ }^{40}$ are integrated to COLUMBUS and have been used to compute the atomic orbitals (AO) integrals as well as the AO gradient integrals.

\section{RESULTS AND DISCUSSION}

\subsection{Vertically Excited States}

As mentioned, $16 \mathrm{C}_{\mathrm{s}}$ states $\left(10 \mathrm{~A}^{\prime}+6 \mathrm{~A}^{\prime \prime}\right)$, including the ground state, have been calculated, which correspond to 11 states at the $\mathrm{C}_{3 \mathrm{v}}$ symmetry. These vertically excited states are assigned to the following excitations: $n_{e} \sigma^{*}\left(1^{1} \mathrm{E}\right) ; \mathrm{n}_{\mathrm{e}} 4 \mathrm{~s}(\mathrm{Cl})\left(2{ }^{1} \mathrm{E}\right) ; \mathrm{n}_{\mathrm{e}} 4 \mathrm{p}_{\mathrm{e}}(\mathrm{Cl})\left(3^{1} \mathrm{E}, 2^{1} \mathrm{~A}_{1}\right.$, and $\left.1^{1} \mathrm{~A}_{2}\right) ; \mathrm{n}_{\mathrm{e}} 3 \mathrm{~s}(\mathrm{C})+\mathrm{n}_{\mathrm{e}} 4 \mathrm{~s}(\mathrm{Cl})\left(4^{1} \mathrm{E}\right) ; \sigma \sigma^{*}+\sigma 4 \mathrm{~s}(\mathrm{Cl})+\mathrm{n}_{\mathrm{F}} \sigma^{*}\left(3^{1} \mathrm{~A}_{1}\right) ; \sigma 4 \mathrm{~s}(\mathrm{Cl})+\sigma 3 \mathrm{~s}(\mathrm{C})+\sigma \sigma^{*}$ $\left(4^{1} \mathrm{~A}_{1}\right) ; \sigma 4 \mathrm{p}_{\mathrm{e}}(\mathrm{Cl})\left(5^{1} \mathrm{E}\right) ; \sigma 3 \mathrm{~s}+\sigma 4 \mathrm{~s}(\mathrm{Cl})\left(5^{1} \mathrm{~A}_{1}\right)$. A detailed description of the vertically excited states is given in Table 2, including energies calculated at the MR-CISD, MR-CISD + Q and MR-AQCC levels, characters and weights of each state, oscillator strengths, and $<\mathbf{r}^{2}>$ expectation values obtained at the MR-CISD level. Comparison with experimental results ${ }^{14}$, 41-43 is also provided.

In the region of interest, the experimental $\mathrm{CF}_{3} \mathrm{Cl}$ spectrum features four bands. ${ }^{10,14}$ 41-43 The experimental values for Bands 2-4 were determined by fitting the original spectral data from refs. ${ }^{14,41}$ with a sum of six Gaussian functions in the region from 8.5 to $14.2 \mathrm{eV}$. These results are also shown in Table 2. 
The lowest band, corresponding to the $n \sigma^{*}\left(1^{1} \mathrm{E}\right)$ state, has its maximum at $7.7 \mathrm{eV}$ and was revealed via electron energy loss spectroscopy due to its feeble intensity $(f=0.003)$. It has also been discussed theoretically in ref. ${ }^{20}$ The present MR-CISD+Q predicts its vertical excitation at $8.32 \mathrm{eV}$ with $f=0.011$. In ref. ${ }^{19}$, a vertical excitation of $8.07 \mathrm{eV}(f=0.003)$ has been obtained for this band at MR-AQCC/aug-cc-pVTZ level with a valence active space using a geometry optimized at the same level. This result was obtained with a geometry whose $\mathrm{C}-\mathrm{Cl}$ distance is slightly larger $(1.766 \AA)$ than the experimental value $(1.751 \AA)$. Here, a value of $8.20 \mathrm{eV}$ has been obtained at the MR-AQCC/refl level, but at the experimental geometry (see Table 2). If the same level is applied, but now to the optimized geometry of ref. $^{20}, 8.08 \mathrm{eV}$ is obtained, which means (i) the refl space has similar accuracy to the valence space (at least for the $\sigma^{*}$ state) and (ii) the excitation energy of $\sigma^{*}$ is sensitive to the $\mathrm{C}-\mathrm{Cl}$ distance.

Table 2. Vertical excitation energies $\left(\Delta E_{v}, \mathrm{eV}\right),<\mathbf{r}^{2}>$ values, and oscillator strengths $(f)$ for the $\mathrm{CF}_{3} \mathrm{Cl}$ molecule obtained at the MR-CISD/refl level with the B1 basis set. $\Delta E_{v}$ obtained at MR$\mathrm{CISD}+\mathrm{Q}$ and MR-AQCC levels are also included. Experimental band maxima $\left(\Delta E_{m}, \mathrm{eV}\right)$ and oscillator strengths for Band 1 are from Ying et al. ${ }^{43}$ For Bands 2-4, experimental data are from Ali. ${ }^{14}$ The experimental data in parenthesis are from Au et al. ${ }^{41}$

\begin{tabular}{|c|c|c|c|c|c|c|c|c|c|}
\hline \multicolumn{7}{|c|}{ Theory } & \multicolumn{3}{|c|}{ Experimental } \\
\hline \multirow[t]{2}{*}{ State } & \multicolumn{3}{|c|}{$\Delta E_{v}(\mathrm{eV})$} & \multirow[t]{2}{*}{$f$} & \multirow[t]{2}{*}{$<\mathbf{r}^{2}>\left(\mathrm{a}_{0}^{2}\right)$} & \multirow[t]{2}{*}{ Main configuration } & \multirow[t]{2}{*}{ Band } & \multirow[t]{2}{*}{$\Delta E_{m}(\mathrm{eV})$} & \multirow[t]{2}{*}{$f$} \\
\hline & $\mathrm{CI}$ & $\mathrm{CI}+\mathrm{Q}$ & AQCC & & & & & & \\
\hline $1^{1} \mathrm{~A}_{1}{ }^{\mathrm{a}}$ & 0.00 & 0.00 & 0.00 & - & 72.06 & $(0.83) \mathrm{gs}$ & & & \\
\hline $1^{1} \mathrm{E}$ & 8.41 & 8.32 & 8.20 & 0.011 & 76.92 & $(0.79) \mathrm{n}_{\mathrm{e}} \sigma^{*}$ & 1 & 7.7 & 0.003 \\
\hline $2^{1} \mathrm{E}$ & 9.64 & 9.67 & 9.56 & 0.201 & 117.07 & $(0.68) n_{e} 4 s+(0.15) n_{e} 3 s$ & 2 & $\begin{array}{c}9.70 \\
(9.70)\end{array}$ & $\begin{array}{r}0.125 \\
(0.161)\end{array}$ \\
\hline $2^{1} \mathrm{~A}_{1}$ & 10.78 & 10.79 & 10.61 & 0.014 & 149.50 & $(0.85) n_{\mathrm{e}} 4 \mathrm{p}_{\mathrm{e}}$ & 3 & $\begin{array}{l}10.60 \\
(10.57)\end{array}$ & $\begin{array}{r}0.068 \\
(0.110)\end{array}$ \\
\hline $3^{1} \mathrm{E}$ & 10.78 & 10.79 & 10.61 & 0.001 & 149.50 & $(0.83) n_{e} 4 p_{e}$ & & & \\
\hline $1^{1} \mathrm{~A}_{2}$ & 10.78 & 10.79 & 10.61 & 0.000 & 149.50 & $(0.85) n_{e} 4 p_{e}$ & & & \\
\hline $4^{1} \mathrm{E}$ & 10.90 & 10.88 & & 0.000 & 152.07 & $(0.69) n_{e} 3 s+(0.14) n_{e} 4 s$ & & & \\
\hline $3^{1} \mathrm{~A}_{1}$ & 13.12 & 12.53 & & 0.790 & 88.42 & $\begin{array}{l}(0.51) \sigma \sigma^{*}+(0.20) \sigma 4 \mathrm{~s}+ \\
(0.12) n_{\mathrm{F}} \sigma^{*}\end{array}$ & 4 & $\begin{array}{c}11.58 \\
(11.58)\end{array}$ & $\begin{array}{c}0.227 \\
(0.268)\end{array}$ \\
\hline $4^{1} \mathrm{~A}_{1}$ & 13.85 & 13.21 & & 0.024 & 107.7 & $\begin{array}{l}(0.43) \sigma 4 \mathrm{~s}+(0.24) \sigma 3 \mathrm{~s}+ \\
(0.11) \sigma \sigma^{*}\end{array}$ & & & \\
\hline $5^{1} \mathrm{E}$ & 14.70 & 14.13 & & 0.014 & 149.13 & $(0.83) \sigma 4 p_{e}$ & & & \\
\hline $5^{1} \mathrm{~A}_{1}$ & 14.87 & 14.15 & & 0.051 & 150.16 & $(0.58) \sigma 3 \mathrm{~s}+(0.20) \sigma 4 \mathrm{~s}$ & & & \\
\hline
\end{tabular}

${ }^{\mathrm{a}}$ Ground-state energies: -796.790689165098 (MR-CISD); -796.931223965361 (MR-CISD+Q); -796.9701875737 (MR-AQCC). 
We recall that the experimental band maximum does not correspond to the vertical excitation energy, which is systematically displaced to the blue by $\sim 0.1-0.2 \mathrm{eV}^{44}$ Thus, in the comparison above, a band maximum at $7.7 \mathrm{eV}$ should actually correspond to a vertical excitation of about 7.8-7.9 eV, which significantly reduces the computational error. Throughout the paper, we still draw comparisons to the band maximum, as this is the hard value delivered by the experiments. Nevertheless, we should bear this blueshift in mind when evaluating the accuracy of the calculations.

Next in energy, the experiments show a bright band at $9.70 \mathrm{eV}$, and a weaker band at $10.60 \mathrm{eV} .^{10,14,41-42}$ At MR-CISD+Q, these values are at 9.67 and $10.79 \mathrm{eV}$ (Table 2). The bright band (band 2) corresponds to the excitations into the $2^{1} \mathrm{E}$ state, with clear $3 \mathrm{~s} / 4 \mathrm{~s}$ Rydberg character $\left(<\mathbf{r}^{2}>=117 \mathrm{a}_{0}^{2}\right)$. The weaker band (band 3) contains excitations into the quasi-four-fold degenerate $3{ }^{1} \mathrm{E}, 2^{1} \mathrm{~A}_{1}$, and $1{ }^{1} \mathrm{~A}_{2}$ states, also with Rydberg character $\left(4 \mathrm{p}_{\mathrm{e}}\right)$, and the $4{ }^{1} \mathrm{E}(3 \mathrm{~s} / 4 \mathrm{~s})$ state.

From the formal standpoint, the occurrence of both 3s and 4s Rydberg orbitals in the ground-state minimum region (at $\mathrm{C}-\mathrm{Cl} \sim 1.7 \AA$ ) leads to appearance of two states formed from the admixture of the $n_{e} 3 s$ and $n_{e} 4 s$ configurations $\left(2{ }^{1} \mathrm{E}\right.$ and $4{ }^{1} \mathrm{E}$, see Table 2$)$. In the $2^{1} \mathrm{E}$, contributing to band 2, one has an anti-symmetric, while in $4^{1} \mathrm{E}$ (contributing to band 3 ), one has a symmetric combination of these two configurations.

A strong band (band 4) comes next, with experimental maximum at $11.58 \mathrm{eV}(f=$ $0.227-0.268$ ). The main vertical excitation to this band computed at MR-CISD+Q is at 12.53 $\mathrm{eV}(f=0.790)$, corresponding to a valence $\left(\sigma \sigma^{*}\right)$ excitation into the $3{ }^{1} \mathrm{~A}_{1}$ state. The strong deviation between theory and experiment by about $0.95 \mathrm{eV}$ (and also in the oscillator strength, which is off by a factor 3), indicates the limits of the current level. Such large blueshift is a well-known problem in this class of methods, mainly arising from insufficient dynamic $\sigma$ polarization (see, e.g., Wu et al. ${ }^{45}$ ). In the case of $\mathrm{CF}_{3} \mathrm{Cl}$, to correct for such effect, we would have to include the C-F $\sigma$ orbitals in the active space to allow them to respond to the $\mathrm{C}-\mathrm{Cl} \sigma$ polarization (which is computationally unaffordable). The inaccuracy of the MRCI oscillator strength is also connected to the dynamic $\sigma$ polarization effect but at another level. If dynamic $\sigma_{\mathrm{CF}}$ polarization were considered, it would lead to $\sigma_{\mathrm{Cl}}$ contraction, ${ }^{46}$ reducing the predicted oscillator strength. 
The need for larger CI expansions to describe band 4 is also implied by the significant Davidson corrections (+Q) obtained for the $3{ }^{1} \mathrm{~A}_{1}$ and the other states contributing to this band. In fact, few additional Rydberg states, not included in this study, are expected in the range from 11.48 to $12.31 \mathrm{eV} .^{47}$ Thus, they are interspersed between the $4^{1} \mathrm{E}$ and $3{ }^{1} \mathrm{~A}_{1}$ states, which can significantly affect the properties of these two states. To the best of our knowledge, it is the first time that the four highest lying states shown in Table 2 are studied for $\mathrm{CF}_{3} \mathrm{Cl}$. Some high-lying states in the case of $\mathrm{CH}_{3} \mathrm{Cl}$ also involve excitations from $\sigma$ to Rydberg orbitals, ${ }^{17-18}$ but in that case, they have much lower multiconfigurational character. For both systems, the state containing the $\sigma \sigma^{*}$ configuration leads to the most intense transition (cf. Table 2 and also Table 1 of ref. ${ }^{18}$ ). However, a significant difference is that, while for $\mathrm{CH}_{3} \mathrm{Cl}$ this configuration has a small (though non-negligible) weight (in the $4{ }^{1} \mathrm{~A}_{1}$ state ${ }^{18}$ ), for $\mathrm{CF}_{3} \mathrm{Cl}$ it appears as the main configuration for one of the studied states, $3{ }^{1} \mathrm{~A}_{1}$ (see Table 2).

Although large deviations have been obtained for $1^{1} \mathrm{E}$ and $3{ }^{1} \mathrm{~A}_{1}$, the full set of states reported here improves considerably the theoretical description of the spectrum of vertically excited states of $\mathrm{CF}_{3} \mathrm{Cl}$. Moreover, a complete description of the vertical excited states at multireference level including all missing Rydberg states (in the studied energy range) is currently computationally impracticable. In the next sections, we apply MR-CISD wavefunctions to investigate the photochemistry of $\mathrm{C}-\mathrm{Cl}$ bond breakage, focusing mainly on excitations up to band 3, where we have succeeded to deliver a semi-quantitatively correct description of the excited states in the Franck-Condon region.

Additional information about the absorption spectrum, including comparison to other methods, is provided in the Supporting Information.

\subsection{Potential Energy curves and Photodissociation Pathways}

Potential energy curves along the $\mathrm{C}-\mathrm{Cl}$ coordinate for ground-state relaxed geometries have been calculated under $\mathrm{C}_{\mathrm{s}}$ symmetry restriction for all electronic states. They are shown in Figure 1 for the corresponding $\mathrm{C}_{3 \mathrm{v}}$ states. At the right, the relaxed dissociation limits, which are discussed later in Section 3.6, are shown as well. 


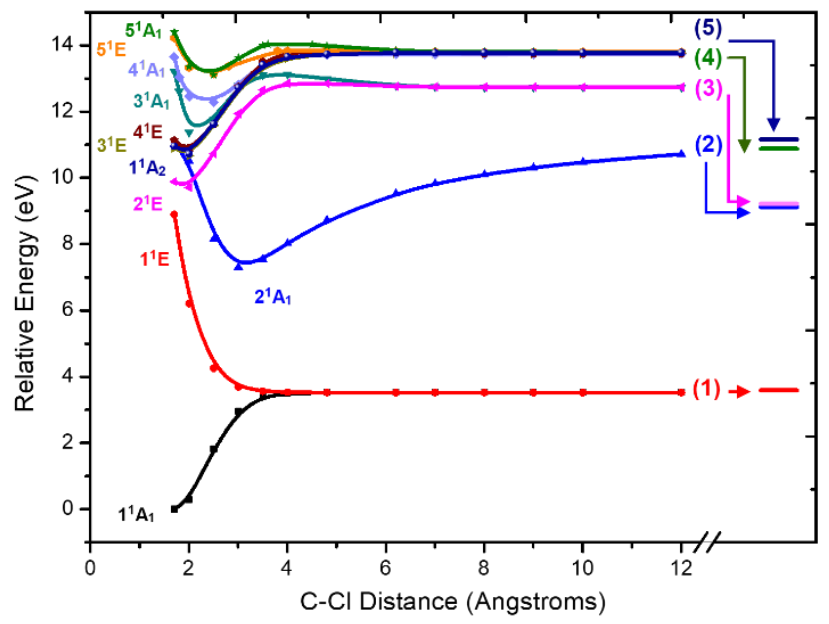

Figure 1. Potential energy curves along the $\mathrm{C}-\mathrm{Cl}$ coordinate for ground-state relaxed geometries. Calculated at the MR-CISD/refl/B1 level. Dissociation limits are (in $\mathrm{C}_{3 \mathrm{v}}$ notation): (1) $\mathrm{CF}_{3}\left(2 \mathrm{p}_{\sigma}(\mathrm{C}), 1^{2} \mathrm{~A}_{1}\right)+\mathrm{Cl}\left({ }^{2} \mathrm{P}\right) ;(2) \mathrm{CF}_{3}{ }^{+}\left(1^{1} \mathrm{~A}_{1}\right)+\mathrm{Cl}^{-}\left({ }^{1} \mathrm{~S}\right) ;(3) \mathrm{CF}_{3}\left(3 \mathrm{~s}, 2^{2} \mathrm{~A}_{1}\right)+\mathrm{Cl}\left({ }^{2} \mathrm{P}\right) ;$ (4) $\mathrm{CF}_{3}\left(3 \mathrm{p}_{\sigma}\right.$, $\left.3^{2} \mathrm{~A}_{1}\right)+\mathrm{Cl}\left({ }^{2} \mathrm{P}\right) ;(5) \mathrm{CF}_{3}\left(3 \mathrm{p}_{\mathrm{e}}, 1^{2} \mathrm{E}\right)+\mathrm{Cl}\left({ }^{2} \mathrm{P}\right)$. At the right, the dissociation limits computed at the same level for the state-specific relaxed geometry are indicated.

The calculation of a potential energy profile like in Figure 1 always implies in certain arbitrary choice of the geometries. Ideally, the geometries should be optimized for the state that the molecule populates at each distance. Nevertheless, when multiple states are calculated, there is not a unique choice. Throughout this paper, unless otherwise stated, we work on ground-state relaxed geometries. With such a choice, an energy profile like in Figure 1 strictly tells the energy spectrum felt by a molecule slowly dissociating in the ground state. This choice has the side-effect of destabilizing the excited states, and this effect can be already noticed in the striking differences between the asymptotic levels of the curves and the corresponding relaxed dissociation limit. Despite the geometry representation chosen for the profiles, the topology of the curves should still be constant. The crossing and avoided crossings arising from the state transformations along the dissociation may change in energy and position, but they still occur qualitatively in the same way for geometries relaxed in another state.

Dissociation along the two lowest lying potential energy curves leads to the $\mathrm{CF}_{3}$ and $\mathrm{Cl}$ fragments in their corresponding electronic ground states (channel (1) of Figure 1). The character of the molecular orbitals smoothly changes as the $\mathrm{C}-\mathrm{Cl}$ interatomic distance 
increases, from the initial set of MOs described above to the expected orbitals belonging to the isolated fragments. That is, from the $\sigma$ and $\sigma^{*}$ molecular orbitals at $\mathrm{CF}_{3} \mathrm{Cl}$, to the $\mathrm{n}_{\sigma}(\mathrm{Cl})$ and $2 p_{\sigma}(C)$ orbitals at the dissociation limit. It is accompanied by a change of ground state configuration from the $(\sigma)^{2}\left(\sigma^{*}\right)^{0}$ at the minimum to $\left(\mathrm{n}_{\sigma}\right)^{1}\left(2 \mathrm{p}_{\sigma}\right)^{1}$ at the dissociation limit. Avoided crossings are also responsible for the wavefunction character changes, which guarantee the correct dissociation limit, as discussed later. The potential energy of the first excited state, vertically assigned as $\left(n_{e}\right)^{1}\left(\sigma^{*}\right)^{1}$, evolves to the $\left(n_{e}\right)^{1}\left(2 p_{\sigma}\right)^{1}$ configuration along a typical repulsive curve. It also leads to the ground-state dissociation limit (see Figure 1), as the three $\mathrm{n}(\mathrm{Cl})$ orbitals become degenerate at very large distances.

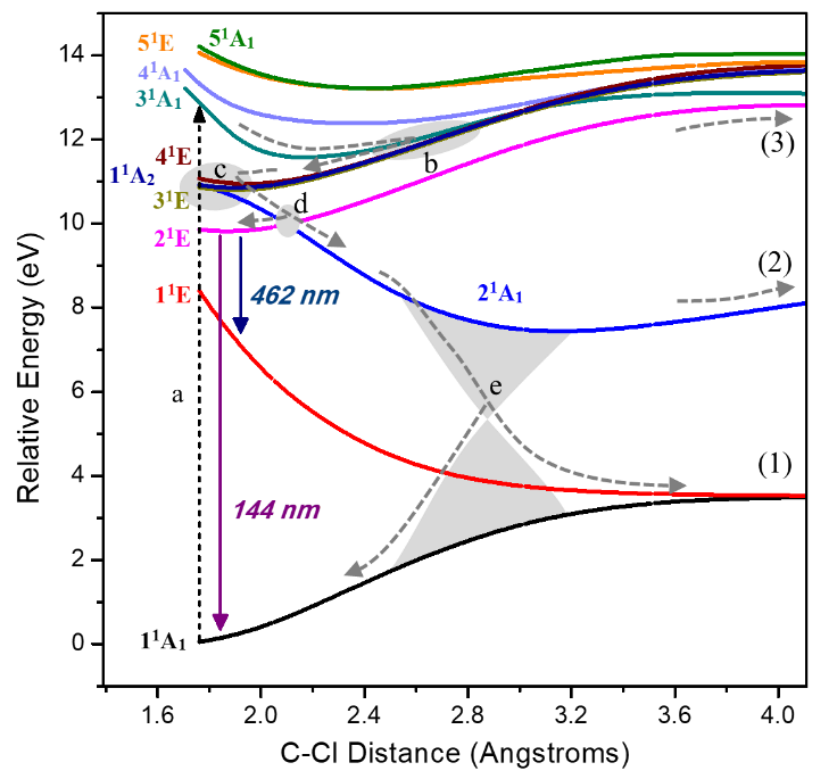

Figure 2. Detailed view of the region between 1.8 and $4 \AA$ of Figure 1 . The vertical dashed arrow (a) indicates a Franck-Condon absorption into the bright $3^{1} \mathrm{~A}_{1}$ state from which nonadiabatic transitions start. Shaded areas (b-e) indicate important regions of state crossings. Possible fluorescence emissions from $2^{1} \mathrm{E}$ are also shown. The fluorescence $\lambda$ values have been computed at the MR-CISD+Q/refl level.

As the $\mathrm{C}-\mathrm{Cl}$ interatomic distance increases to $c a .2 .5 \AA$, the Rydberg orbitals' character also smoothly changes from a Rydberg 4s (centered at the $\mathrm{Cl}$ atom, at the equilibrium geometry) to a Rydberg $3 \mathrm{p}_{\sigma}$ (centered at the $\mathrm{C}$ atom). Rydberg $4 \mathrm{p}_{\mathrm{e}}(\mathrm{Cl})$ orbitals undergo similar changes to $3 p_{\mathrm{e}}(\mathrm{C})$. Upon disappearance of $4 \mathrm{~s}$ orbital observed at the $\mathrm{CF}_{3}$ 
$\left(2^{2} \mathrm{~A}_{1}\right)+\mathrm{Cl}\left({ }^{2} \mathrm{P}\right)$ dissociation limit along the $2^{1} \mathrm{E}$ curve (channel (3)), the vertically-assigned configuration $n_{e} 4 s$ becomes the $n_{e} 3 s$.

In Figure 2, we deliver a more detailed picture of the potential energy curves in the short $\mathrm{C}-\mathrm{Cl}$ region. After high-energy excitation into the bright $3{ }^{1} \mathrm{~A}_{1}$ state (a), there is a clear nonadiabatic pathway to transfer the population all way down to the $2{ }^{1} \mathrm{E}_{1}$ state, indicated by the sequence of dashed arrows. The main nonadiabatic features in this energy region are (i) the multi-state crossing involving $3^{1} \mathrm{~A}_{1}, 4^{1} \mathrm{E}, 1^{1} \mathrm{~A}_{2}$, and $3^{1} \mathrm{E}$ at $2.8 \AA$ (indicated by the shaded area b); (ii) the multi-state crossing involving $4^{1} \mathrm{E}, 1^{1} \mathrm{~A}_{2}, 3^{1} \mathrm{E}$, and $2^{1} \mathrm{~A}_{1}$ at $1.8 \AA$ (shaded area c); and (iii) the $2^{1} \mathrm{E} / 2^{1} \mathrm{~A}_{1}$ crossing at $2 \AA$ (shaded area d). At the $2^{1} \mathrm{E}_{1}\left(\mathrm{n}_{\mathrm{e}} 4 \mathrm{~s}\right)$ state, which can also be directly excited, fluorescence can (in principle) take place, or the molecule can still internally convert to the ion-pair state through the $2^{1} \mathrm{E} / 2^{1} \mathrm{~A}_{1}$ crossing. The relaxation of the $2^{1} \mathrm{E}_{1}$ state is discussed in Section 3.3; the competition between fluorescence and internal conversion is discussed in Section 3.8. Relaxation in the $2^{1} \mathrm{~A}_{1}$ ion-pair state (shaded area e) leads to a conical intersection between it and the $1^{1} \mathrm{~A}_{1}$ (not shown in the figure), which is discussed in more details in Section 3.7. During this nonadiabatic relaxation, depending on the vertical excitation, the molecule may dissociate forming neutral fragments along channels (1) and (3) and charged fragments in the channel (2) (see Section 3.6).

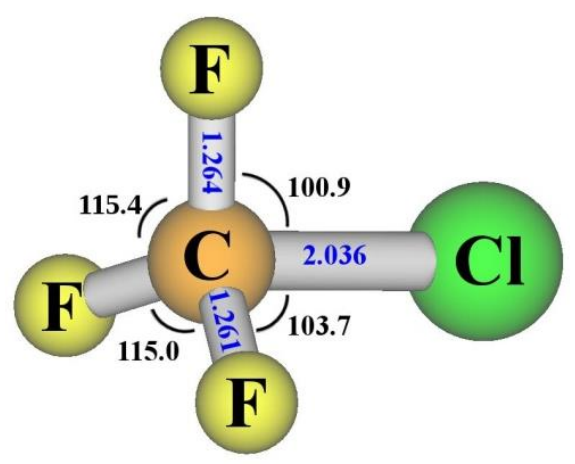

Figure 3. Optimized structure of the $n_{e} 4 s$ state $\left(3^{1} \mathrm{~A}^{\prime}\right)$ computed at the MR-CISD/ref2/B1 level.

\subsection{Characterization of the $n_{e} 4 s$ state}

Upon excitation into the $\mathrm{n}_{\mathrm{e}} 4 \mathrm{~s}\left(2^{1} \mathrm{E}\right.$; or $3^{1} \mathrm{~A}^{\prime}+2^{1} \mathrm{~A}^{\prime \prime}$ in $\left.\mathrm{C}_{\mathrm{s}}\right)$ state, the system is subjected to the Jahn-Teller (JT) effect, thus leading to symmetry lowering from $\mathrm{C}_{3 \mathrm{v}}$ to $\mathrm{C}_{\mathrm{s}}$. Full geometry 
optimization of the $3^{1} \mathrm{~A}^{\prime}$ state indicates a small JT effect, as the departure from $\mathrm{C}_{3 \mathrm{v}}$ symmetry is relatively small (see Figure 3), leading to an energy difference between $3^{1} \mathrm{~A}^{\prime}$ and its counterpart $\left(2^{1} \mathrm{~A}^{\prime \prime}\right)$ of only $0.03 \mathrm{eV}$ (at the MR-CISD+Q/refl level). The $\mathrm{C}-\mathrm{Cl}$ interatomic distance at the minimum energy geometry of $n_{e} 4 \mathrm{~s}$ is $2.036 \AA$. The main configurations at the optimized geometry of $3^{1} \mathrm{~A}^{\prime}$ are $0.60 \mathrm{n}_{\mathrm{e}} 4 \mathrm{~s}+0.22 \mathrm{n}_{\mathrm{e}} 3 \mathrm{~s}$ (MR-CISD/refl).

Table 3. Vibrational frequencies, energy differences $(\Delta \mathrm{E}$, in $\mathrm{eV})$ and oscillator strengths to lower states, for the $n_{e} 4 s$ state, computed at the MR-CISD level with the B1 basis set. Vibrational frequencies of $\mathrm{CF}_{3} \mathrm{Cl}$ in the ground state are also given for comparison.

\begin{tabular}{|c|c|c|}
\hline \multicolumn{3}{|l|}{ Vibrational frequencies } \\
\hline Description & ground $^{\mathrm{a}}$ & $n_{e} 4 s^{b}$ \\
\hline $\mathrm{ClCF}$ angular deformation $\left(\mathrm{A}^{\prime \prime}\right)$ & -- & 176.0 \\
\hline $\mathrm{C}-\mathrm{Cl}$ stretch & -- & 236.9 \\
\hline $\mathrm{ClCF}$ angular deformation $\left(\mathrm{A}^{\prime}\right)$ & -- & 273.2 \\
\hline $\mathrm{ClCF}$ angular deformation & $358.5^{\mathrm{c}}$ & -- \\
\hline $\mathrm{C}-\mathrm{Cl}$ stretch & 494.4 & -- \\
\hline $\mathrm{CF}_{3}$ angular deformation $\left(\mathrm{A}^{\prime}\right)$ & $592.2^{\mathrm{c}}$ & 576.0 \\
\hline $\mathrm{CF}_{3}$ angular deformation $\left(\mathrm{A}^{\prime \prime}\right)$ & -- & 576.1 \\
\hline $\mathrm{CF}_{3}$ umbrella mode $\left(\mathrm{A}^{\prime}\right)$ & 836.3 & 651.4 \\
\hline $\mathrm{CF}_{3}$ symmetric stretch $\left(\mathrm{A}^{\prime}\right.$, breathing mode $)$ & 1204.7 & 1018.0 \\
\hline CF stretch $\left(\mathrm{A}^{\prime}\right)$ & $1345.3^{\mathrm{c}}$ & 1511.6 \\
\hline CF stretch $\left(\mathrm{A}^{\prime \prime}\right)$ & -- & 1513.2 \\
\hline \multicolumn{3}{|l|}{ Electronic Properties $\left(\mathrm{n}_{\mathrm{e}} 4 \mathrm{~s}\right)$} \\
\hline Lower state & $\Delta \mathrm{E}^{\mathrm{d}}$ & $f\left(\times 10^{3}\right)^{\mathrm{b}}$ \\
\hline$n \sigma^{*}$ & $\begin{array}{l}2.83^{\mathrm{e}} \\
(438 \mathrm{~nm})\end{array}$ & 2.167 \\
\hline Ground & $\begin{array}{l}8.61 \\
(144 \mathrm{~nm})\end{array}$ & 55.401 \\
\hline
\end{tabular}

${ }^{\mathrm{a}}$ Computed with the valence space; ${ }^{\mathrm{b}}$ computed with the ref2 space; ${ }^{\mathrm{c}}$ doubly degenerate vibrations; ${ }^{\mathrm{d}}$ singlepoint calculations performed at the MR-CISD $+\mathrm{Q} /$ refl level; ${ }^{\mathrm{e}}$ average value.

Frequency calculation shows the $n_{e} 4 s$ state as a minimum, and its vibrational frequencies, along with the oscillator strengths to the lower states, are given in Table 3. As can be seen from this table, the previously doubly degenerated $\mathrm{Cl}-\mathrm{C}-\mathrm{F}$ angular deformation 
of the ground state (in $358.5 \mathrm{~cm}^{-1}$ ) is split into two vibrations with significantly lower frequencies $\left(176.0\right.$ and $\left.273.2 \mathrm{~cm}^{-1}\right)$ for the $\mathrm{n}_{\mathrm{e}} 4 \mathrm{~s}$ state. Similarly, the $\mathrm{C}-\mathrm{Cl}$ stretching frequency is also reduced, but the effect is much stronger, which is consistent with an increase of 0.262 $\AA$ (from 1.774 to $2.036 \AA$ ) of the $\mathrm{C}-\mathrm{Cl}$ bond distance. Thus, this bond is significantly weakened in the $\mathrm{n}_{\mathrm{e}} 4 \mathrm{~s}$ state. A tiny reduction has been obtained for the degenerated $\mathrm{CF}_{3}$ angular deformation mode (from 592.2 to $576 \mathrm{~cm}^{-1}$ ). However, for the umbrella deformation mode $\left(836.3 \mathrm{~cm}^{-1}\right)$ the reduction is much larger, which can be explained by its significant coupling with the $\mathrm{C}-\mathrm{Cl}$ stretching mode. A similar effect is observed for the $\mathrm{CF}_{3}$ breathing mode. However, for the degenerated CF stretching mode, the increase from 1345.3 to 1512 $\mathrm{cm}^{-1}$ (mean value) can be explained by the stronger $\mathrm{C}-\mathrm{F}$ bonds in the $\mathrm{n}_{\mathrm{e}} 4 \mathrm{~s}$ state (with bond distances of 1.261 and $1.264 \AA$, as compared with the value of $1.307 \AA$ in the ground state).

\subsection{Potential energy curves for the ${ }^{1} \mathrm{~A}_{1}$ states}

The calculated potential energy curves for the ${ }^{1} \mathrm{~A}_{1}$ states, in the region from 1.7 to $6.2 \AA$, are shown in Figure 4 (a) and (b). Four avoided crossings can be clearly identified. The first one at $\sim 1.7 \AA$ makes the configuration $\sigma \sigma^{*}+\sigma 3 \mathrm{~s}$, previously in the $4{ }^{1} \mathrm{~A}_{1}$ state, to become the $\sigma \sigma^{*}+\sigma 4 \mathrm{~s}$ configuration in the $3^{1} \mathrm{~A}_{1}$ state. The explanation for this change from $\sigma 3 \mathrm{~s}$ to $\sigma 4 \mathrm{~s}$ is the near degeneracy between the $4 \mathrm{~s}(\mathrm{Cl})$ and $3 \mathrm{~s}(\mathrm{C})$ orbitals caused by the quantum defects $\delta_{4 \mathrm{~s}}$ $=2.09\left(\right.$ ref. $\left.^{47}\right)$ and $\delta_{3 \mathrm{~s}}=0.912,{ }^{16}$ resulting in $4-\delta_{4 \mathrm{~s}} \cong 3-\delta_{3 \mathrm{~s}}$. Another evidence for such near degeneracy is the strong coupling between the $\sigma 3 \mathrm{~s}$ and $\sigma 4 \mathrm{~s}$ configurations, leading to a symmetric and anti-symmetric combination between them in the $5^{1} \mathrm{~A}_{1}$ and $3{ }^{1} \mathrm{~A}_{1}$ states, respectively (at $\sim 1.7 \AA$ ). At $\sim 2.0 \AA$, these combinations are observed between the $5^{1} \mathrm{~A}_{1}$ and $4{ }^{1} \mathrm{~A}_{1}$ states.

The second avoided crossing takes place at $\sim 2.0 \AA$, bringing the $\sigma \sigma^{*}$ configuration to the $2^{1} A_{1}$ state, while the $n_{e} 4 p_{e}$ configuration (which later becomes $n_{e} 3 p_{e}$ ) is transferred to the $3{ }^{1} A_{1}$ state (see Figure $4(a)$ ). The change from $n_{e} 4 p_{e}$ to $n_{e} 3 p_{e}$ configuration is due to the change of localization of the $\mathrm{np}_{\mathrm{e}}$ Rydberg orbitals, from the $\mathrm{Cl}$ to the $\mathrm{C}$ atom, in the region between $\sim 2.0$ and $2.5 \AA$. The same holds for the $4 \mathrm{~s}$ orbital, which becomes the $3 p_{\sigma}$ orbital.

In the case of the third avoided crossing at $\sim 3 \AA$, the $n_{\mathrm{e}} 3 \mathrm{p}_{\mathrm{e}}$ and $\sigma 3 \mathrm{~s}$ configurations are interchanged between the $3{ }^{1} \mathrm{~A}_{1}$ and $4{ }^{1} \mathrm{~A}_{1}$ states (see Figure 4 (a)). At this point, the $3{ }^{1} \mathrm{~A}_{1}$, 
$1^{1} \mathrm{~A}_{2}, 3^{1} \mathrm{E}$, and $4^{1} \mathrm{E}$ states are almost degenerate. The primary configuration of the first three states is $n_{e} 3 p_{e}$, while for the latter it is $n_{e} 3 p_{\sigma}$.

The last avoided crossing is between the $2{ }^{1} \mathrm{~A}_{1}$ and $1^{1} \mathrm{~A}_{1}$ states (at $\sim 2.8 \AA$, see Figure 4 (b)). It brings the ionic configuration $-\left(\mathrm{n}_{\sigma}\right)^{2}\left(2 \mathrm{p}_{\sigma}\right)^{0}$ or $\sigma^{2}\left(2 \mathrm{p}_{\sigma}\right)^{0}$, depending on the $\mathrm{C}-\mathrm{Cl}$ distance - from the $2^{1} \mathrm{~A}_{1}$ to the $1{ }^{1} \mathrm{~A}_{1}$ state and then back to the $2^{1} \mathrm{~A}_{1}$ state. After the avoided crossing, the dominant configuration of the $1{ }^{1} \mathrm{~A}_{1}$ state becomes $n_{\sigma} 2 \mathrm{p}_{\sigma}$, consistent with a homolytic dissociation. This complex state-crossing pattern occurs because the ion-pair state has a minimum that is slightly below the energy of the $n_{\sigma} 2 p_{\sigma}$ state. This minimum is discussed in Section 3.7.
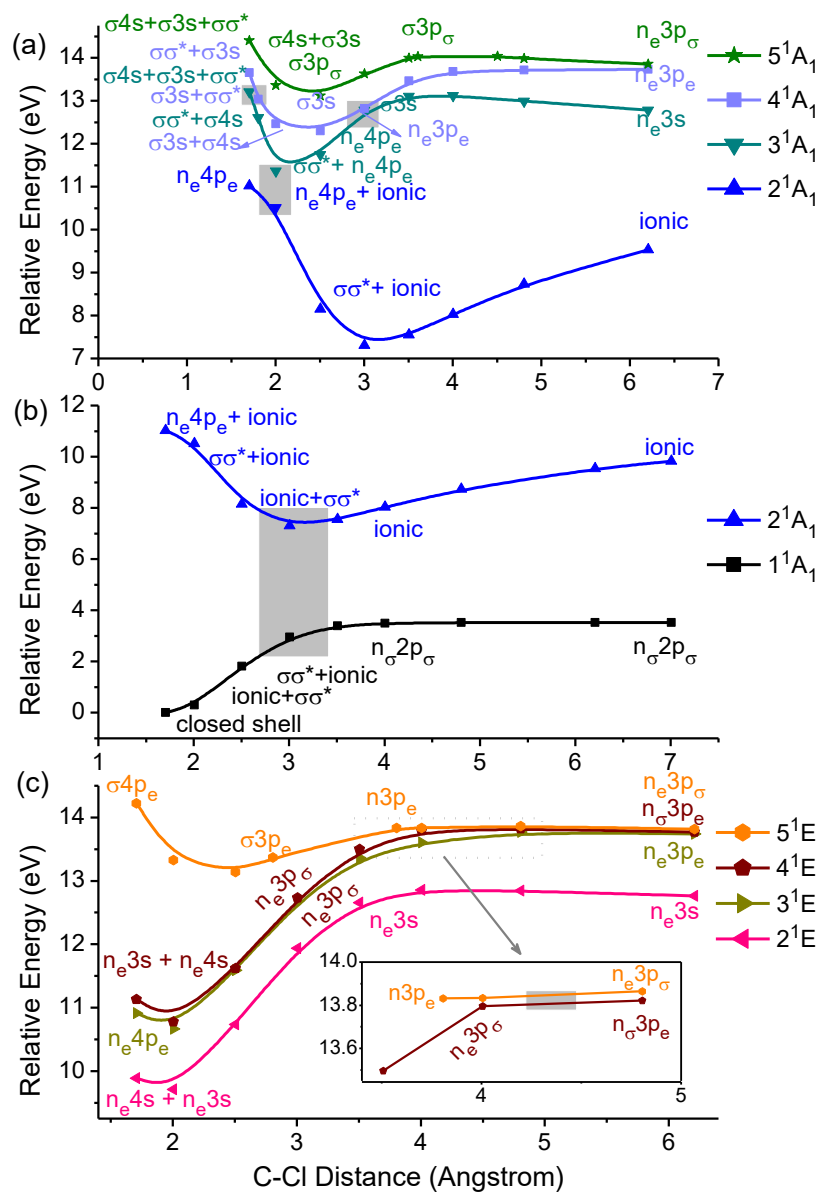

Figure 4. Ground-state relaxed potential energy curves along the $\mathrm{C}-\mathrm{Cl}$ coordinate for: (a) ${ }^{1} \mathrm{~A}_{1}$ states (from 2 to 5); (b) the $1^{1} \mathrm{~A}_{1}$ and $2^{1} \mathrm{~A}_{1}$ states; and (c) ${ }^{1} \mathrm{E}$ states. The shaded areas indicate regions of avoided crossings. The inset in (c) highlights the avoided crossing between the $4^{1} \mathrm{E}$ and $5^{1}$ E states at $\sim 4.3 \AA$. All data at MR-CISD/refl/B1 level. 
An important difference between the $\mathrm{CH}_{3} \mathrm{Cl}$ and $\mathrm{CF}_{3} \mathrm{Cl}$ molecules is the occurrence of an avoided crossing between the $2{ }^{1} \mathrm{~A}_{1}$ (ionic) and $3{ }^{1} \mathrm{~A}_{1}\left(\mathrm{n}_{\sigma} 3 \mathrm{~s}\right)$ states of the former for a $\mathrm{C}-$ $\mathrm{Cl}$ distance of $\sim 15 \AA .{ }^{18}$ In the case of $\mathrm{CF}_{3} \mathrm{Cl}$, the absence of such a crossing can be explained by the larger excitation energy of the 3 s state of the $\mathrm{CF}_{3}$ radical, as compared to that of $\mathrm{CH}_{3}$.

As the $\sigma$ orbital becomes more localized in the $\mathrm{Cl}$ atom (for larger distances), it changes to $\mathrm{n}_{\sigma}$, and the configurations involving this orbital change accordingly. Thus, $\sigma 3 \mathrm{~s}$ and $\sigma 3 p_{\sigma}$ configurations become $n_{\sigma} 3 s$ and $n_{\sigma} 3 p_{\sigma}$, respectively (see Figure 4 (a)). The main contribution to the ionic configuration of the $2^{1} \mathrm{~A}_{1}$ state is associated with an electron transfer from the $2 \mathrm{p}_{\sigma}(\mathrm{C})$ orbital of the $\mathrm{CF}_{3}$ radical to the $\mathrm{Cl}$ atom. However, for $\mathrm{C}-\mathrm{Cl}$ distances larger than $\sim 3 \AA$, another ionic configuration, associated with an electron transfer from the $\mathrm{n}_{\mathrm{F}}$ orbital of the $\mathrm{CF}_{3}$ radical to the $\mathrm{Cl}$ atom, also becomes important, with weights varying from $\sim 0.12$ to 0.19 , for $\mathrm{C}-\mathrm{Cl}$ distances larger than $\sim 3 \AA$. Therefore, for such $\mathrm{C}-\mathrm{Cl}$ distances, the ionic configurations, shown in Figure 4 (a) and (b), are actually an admixture between the two types of ionic configurations. It is important to point out that the $\mathrm{n}_{\mathrm{F}}$ orbital has been included in the active space to guarantee the correct shapes for the $3 p$ orbitals for very large distances.

\subsection{Potential energy curves for the ${ }^{1} \mathrm{E}$ states}

The computed potential energy curves for the ${ }^{1} \mathrm{E}$ states, for $\mathrm{C}-\mathrm{Cl}$ distances in a range from 1.7 to $6.2 \AA$, are shown in Figure 4 (c). As in the case of the ${ }^{1} \mathrm{~A}_{1}$ states, the interaction between the $n_{e} 3 s$ and $n_{e} 4 s$ configurations in the $2^{1} \mathrm{E}$ and $4{ }^{1} \mathrm{E}$ states can be explained by the near degeneracy between the 3 s and 4s Rydberg orbitals.

The $\left(\mathrm{n}_{\mathrm{e}}\right)^{1}\left(4 \mathrm{p}_{\mathrm{e}}\right)^{1}$ and $\left(\mathrm{n}_{\mathrm{e}}\right)^{1}\left(3 \mathrm{p}_{\mathrm{e}}\right)^{1}$ configurations are connected along the $3^{1} \mathrm{E}$ curve (see Figure $4(\mathrm{c})$ ), giving rise to the $\mathrm{CF}_{3}\left(3 \mathrm{p}_{\mathrm{e}}, 1^{2} \mathrm{E}\right)+\mathrm{Cl}\left({ }^{2} \mathrm{P}\right)$ dissociation limit (channel (5) of Figure 1). The $\left(\mathrm{n}_{\mathrm{e}}\right)^{1}\left(4 \mathrm{p}_{\mathrm{e}}\right)^{1}$ configuration is dominant in the $1{ }^{1} \mathrm{~A}_{2}$ curve and is also connected to the $\left(n_{e}\right)^{1}\left(3 p_{e}\right)^{1}$ configuration, observed at larger distances and contributing to the channel (5) too.

Along the $4^{1} E$ curve, the $n_{e} 3 s+n_{e} 4 s$ and the $n_{e} 3 p_{\sigma}$ configurations are connected due to a gradual loss of importance of the $\mathrm{n}_{\mathrm{e}} 3 \mathrm{~s}$ configuration, along with a transformation of the $4 \mathrm{~s}$ orbital into the $3 p_{\sigma}$ orbital (see Figure 4 (c)). In the case of the $5^{1} \mathrm{E}$ curve, the $\sigma 4 \mathrm{p}_{\mathrm{e}}$ configuration first becomes $\sigma 3 p_{e}$ due to a change of localization of the $n p_{e}$ orbital, first 
centered on the $\mathrm{Cl}$ atom $(\mathrm{n}=4)$ and then on the $\mathrm{C}$ atom $(\mathrm{n}=3)$, for larger distances. Afterward, the $\sigma 3 p_{e}$ configuration becomes $n_{\sigma} 3 p_{e}$ due to the transformation of the $\sigma$ orbital in the $n_{\sigma}$ orbital, centered on the $\mathrm{Cl}$ atom.

The only avoided crossing for the ${ }^{1} \mathrm{E}$ states has been observed between the $4^{1} \mathrm{E}$ and $5^{1}$ E states, at $\sim 4.3 \AA$. Such avoided crossing interchanges the $n_{e} 3 p_{\sigma}$ and $n_{\sigma} 3 p_{e}$ configurations between these two states. However, the energy separation after the crossing is so small that they still are part of the same dissociation limit, $\mathrm{CF}_{3}\left(1^{2} \mathrm{E}\right)+\mathrm{Cl}\left({ }^{2} \mathrm{P}\right)$.

\subsection{Dissociation limits}

MR-CISD calculations were done for a $\mathrm{C}-\mathrm{Cl}$ distance of $50 \AA$ to get the dissociation limits. For each limit, the $\mathrm{CF}_{3}$ geometry is relaxed in the corresponding ground or excited state. These relaxed $\mathrm{CF}_{3}$ geometries are reported in Ref. ${ }^{16}$ Similar procedure was used for the ionpair dissociation limit, but relaxing $\mathrm{CF}_{3}{ }^{+}$in the ground state. All relaxed dissociation limits are illustrated in Figure 1 and given in Table 4.

Table 4. Dissociation limits computed at the $\mathrm{C}-\mathrm{Cl}$ distance of $50 \AA$ at $\mathrm{MR}-\mathrm{CISD}+\mathrm{Q} / \mathrm{ref} 1 / \mathrm{B} 1$ level. The values are calculated for the $\mathrm{CF}_{3} / \mathrm{CF}_{3}{ }^{+}$optimized in its final state. Results in parenthesis include ZPE. The exit channels are given as well.

\begin{tabular}{|c|c|c|c|c|}
\hline \multirow[t]{2}{*}{ Exit channels } & \multirow[t]{2}{*}{ Bound states } & \multicolumn{3}{|c|}{ Dissociation limits $(\mathrm{eV})$} \\
\hline & & MR-CISD & MR-CISD+Q & $\begin{array}{c}\text { reference } \\
\text { values }\end{array}$ \\
\hline (1) $\mathrm{CF}_{3}\left(1^{2} \mathrm{~A}_{1}\right)+\mathrm{Cl}\left({ }^{2} \mathrm{P}\right)$ & $1^{1} \mathrm{~A}_{1}+1^{1} \mathrm{E}$ & $\begin{array}{c}3.59 \\
(3.40)\end{array}$ & $\begin{array}{c}3.70 \\
(3.57)\end{array}$ & $3.66^{\mathrm{a}}$ \\
\hline (2) $\mathrm{CF}_{3}{ }^{+}\left(1^{1} \mathrm{~A}_{1}\right)+\mathrm{Cl}^{-}\left({ }^{1} \mathrm{~S}\right)$ & $2^{1} \mathrm{~A}_{1}$ & $\begin{array}{l}9.16 \\
(9.14)\end{array}$ & $\begin{array}{c}9.01 \\
(8.99)\end{array}$ & $9.05^{b}$ \\
\hline (3) $\mathrm{CF}_{3}\left(3 \mathrm{~s}, 2^{2} \mathrm{~A}_{1}\right)+\mathrm{Cl}\left({ }^{2} \mathrm{P}\right)$ & $3{ }^{1} \mathrm{~A}_{1}+2^{1} \mathrm{E}$ & $\begin{array}{c}9.18 \\
(9.17)\end{array}$ & $\begin{array}{c}8.52 \\
(8.51)\end{array}$ & $8.02^{c}$ \\
\hline (4) $\mathrm{CF}_{3}\left(3 \mathrm{p}_{\sigma}, 3^{2} \mathrm{~A}_{1}\right)+\mathrm{Cl}\left({ }^{2} \mathrm{P}\right)$ & $5^{1} \mathrm{~A}_{1}+5^{1} \mathrm{E}$ & $\begin{array}{c}10.88 \\
(10.87)\end{array}$ & $\begin{array}{c}10.33 \\
(10.31)\end{array}$ & $9.87^{\mathrm{c}}$ \\
\hline (5) $\mathrm{CF}_{3}\left(3 \mathrm{p}_{\mathrm{e}}, 1^{2} \mathrm{E}\right)+\mathrm{Cl}\left({ }^{2} \mathrm{P}\right)$ & $4^{1} \mathrm{~A}_{1}+3{ }^{1} \mathrm{E}+4{ }^{1} \mathrm{E}+1^{1} \mathrm{~A}_{2}$ & 11.16 & 10.59 & $10.07^{\mathrm{d}}$ \\
\hline
\end{tabular}

${ }^{a}$ From ref. ${ }^{48}$, ${ }^{b}$ Computed from the values taken from refs. ${ }^{48-49}$ along with the experimental dissociation energy of $\mathrm{CF}_{3} \mathrm{Cl}^{48 \mathrm{c}}$ Taken from the corresponding adiabatic excitation energies of the $\mathrm{CF}_{3}$ radical ${ }^{16}$ at the MR-CISD+Q level summed to the experimental dissociation energy ${ }^{48}(3.66 \mathrm{eV}) ;{ }^{\mathrm{d}}$ In this case, the ground-state dissociation energy used $(3.74 \mathrm{eV})$ does not include ZPE. 
The reference ground-state dissociation energy reported in Table 4 has been calculated for $0 \mathrm{~K}$ enthalpies available from NIST for $\mathrm{CF}_{3} \mathrm{Cl}_{1} \mathrm{CF}_{3}$, and $\mathrm{Cl}(-702.71,-469.19$,

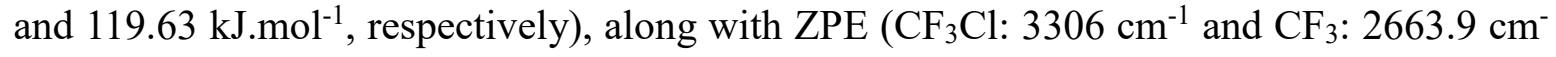
$\left.{ }^{1}\right) .{ }^{48}$ For the ionic channel, the reference dissociation limit has been estimated by taking into account the electron affinity of $\mathrm{Cl}\left(3.613 \mathrm{eV}\right.$, ref. $\left.^{48}\right)$ and the adiabatic ionization energy of $\mathrm{CF}_{3}\left(9.0 \mathrm{eV}\right.$, ref. $\left.^{49}\right)$ summed to the ground state dissociation energy. Adiabatic excitation energies for $\mathrm{CF}_{3}\left(4.36,6.21\right.$, and $6.33 \mathrm{eV}$ for the $3 \mathrm{~s}, 3 \mathrm{p}_{\sigma}$, and $3 \mathrm{p}_{\mathrm{e}}$ states), obtained at MRCISD+Q with the B1 basis set, ${ }^{16}$ have been added to the ground-state dissociation energy to estimate the other reference dissociation limits.

As can be seen from Table 4, there is good agreement between the MR-CISD+Q results and the reference values. For the lowest two channels, the deviation is smaller than $0.1 \mathrm{eV}$, indicating that basis set superposition error (BSSE) should not play a significant role. This conclusion is not surprising given the high quality of the B1 basis set. For the three other channels, the MR-CISD+Q values are about $0.5 \mathrm{eV}$ larger than the reference values, pointing once more to the limitations of the active and reference spaces adopted in this study to describe highly-excited states.

\subsection{Characterization of the $\mathrm{CF}_{3}{ }^{+}+\mathrm{Cl}^{-}$Ion Pair}

As in the case of $\mathrm{CH}_{3} \mathrm{Cl},{ }^{18}$ the profile of the $2^{1} \mathrm{~A}_{1}$ state in Figure 1 suggests the occurrence of a stationary point correlating with the $\mathrm{CF}_{3}{ }^{+}+\mathrm{Cl}^{-}$dissociation channel at $\sim 3 \AA$. Because at this distance one has a small weight of the $\left(n_{F}\right)^{1}\left(2 p_{\sigma}\right)^{1}$ configuration, a full geometry optimization was performed (with the B1 basis set) excluding this orbital from the CAS. The $\mathrm{n}_{\mathrm{F}}$ orbital was moved to the doubly occupied space at both MCSCF and MR-CISD levels to make the calculation feasible.

After the full geometry optimization, the structure of the $\mathrm{CF}_{3}{ }^{+} \ldots \mathrm{Cl}^{-}$ion pair shown in Figure 5 is obtained. As can be seen from this plot, the $\mathrm{CF}_{3}{ }^{+}$group is not planar, and the $\mathrm{F}$ atoms are in a plane whose distance to $\mathrm{Cl}^{-}$is smaller than the $\mathrm{C} \cdots \mathrm{Cl}$ distance. This structure is an extreme on the potential energy surface, belonging to the $\mathrm{C}_{3 \mathrm{v}}$ symmetry group and with the $\mathrm{C}-\mathrm{Cl}$ bond distance much shorter (by $0.5 \AA$ ) than that in the $\mathrm{CH}_{3}{ }^{+\ldots} \mathrm{Cl}^{-}$ion pair. ${ }^{18}$ Although we assumed that this geometry for the $\mathrm{CF}_{3}^{+}{ }^{+\ldots} \mathrm{Cl}^{-}$ion pair is a minimum; we could 
not verify it due to convergence problems in the normal mode analysis caused by the quasidegeneracy of this state with the $1{ }^{1} \mathrm{~A}_{1}$ state. In fact, we discuss later in this section that a conical intersection between the $2^{1} \mathrm{~A}_{1}$ and $1{ }^{1} \mathrm{~A}_{1}$ states lies near this minimum.

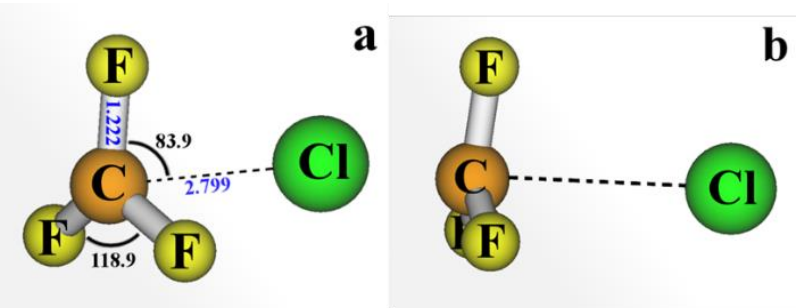

Figure 5. Two different views of the $\mathrm{CF}_{3}{ }^{+\ldots} \mathrm{Cl}^{-}$ion-pair structure at the MR-CISD/valence/B1 level. Important geometric parameters are given in (a). In (b), one can see that the plane containing the $\mathrm{F}$ atoms is slightly closer to the chloride than the $\mathrm{C}$ atom, with a corresponding $\angle_{\text {FFFC }}$ dihedral angle of 12 degrees.

The $\mathrm{CF}_{3}{ }^{+\ldots} \mathrm{Cl}^{-}$ion-pair minimum lies $4.62 \mathrm{eV}$ (4.99 eV with ZPE correction) above the ground-state minimum (MR-CISD+Q/refl/B1 level), and it has a large stabilization energy of $4.4 \mathrm{eV}\left(4.0 \mathrm{eV}\right.$ with ZPE) compared with the $\mathrm{CF}_{3}{ }^{+}$and $\mathrm{Cl}^{-}$species separated by a distance of $50 \AA$. This value makes it much more stable (by $2.42 \mathrm{eV}$ with ZPE) than the $\mathrm{CH}_{3}{ }^{+} \ldots \mathrm{Cl}^{-}$ion pair. ${ }^{18}$ Even after an additional stabilization of the $\mathrm{CH}_{3}{ }^{+} \ldots \mathrm{Cl}^{-}$ion pair due to the $\mathrm{CH}^{\cdots} \mathrm{Cl}$ hydrogen bond formation (now yielding the $\mathrm{H}_{2} \mathrm{CH}^{+\cdots} \mathrm{Cl}^{-}$complex ${ }^{12}$ ), the $\mathrm{CF}_{3}{ }^{+\ldots} \mathrm{Cl}^{-}$ion pair remains considerably more stable (by $1.46 \mathrm{eV}$ ).

As expected, the polarity of the $\mathrm{CF}_{3}^{+}{ }^{+\cdots} \mathrm{Cl}^{-}$ion pair is like that of $\mathrm{CH}_{3}{ }^{+} \cdots \mathrm{Cl}^{-}$, with a dipole moment of $11.56 \mathrm{D}$ (MR-CISD/ref1/B1 level), but with a much larger charge separation (from $\mathrm{CF}_{3}{ }^{+\delta \cdots} \mathrm{Cl}^{-\delta}$ ), with $\delta=1.42$ (from Mulliken's population analysis). This single-point calculation also yields the following ionic configuration: $0.70\left(\mathrm{n}_{\mathrm{F}}\right)^{2}\left(2 \mathrm{p}_{\sigma}\right)^{0}\left(\mathrm{n}_{\sigma}(\mathrm{Cl})\right)^{2}+0.14\left(\mathrm{n}_{\mathrm{F}}\right)^{1}\left(2 \mathrm{p}_{\sigma}\right)^{1}\left(\mathrm{n}_{\sigma}(\mathrm{Cl})\right)^{2}$. Thus, differently from $\mathrm{CH}_{3}{ }^{+\ldots} \mathrm{Cl}^{-}{ }^{18}$ in the case of the $\mathrm{CF}_{3}{ }^{+\ldots} \mathrm{Cl}^{-}$ion pair, the configuration $2 \mathrm{p}_{\sigma} \mathrm{n}_{\sigma}(\mathrm{Cl})$ (or $\sigma \sigma^{*}$, depending on the $\mathrm{C}-\mathrm{Cl}$ distance) has negligible weight. Another important characteristic of the $\mathrm{CF}_{3}^{+}{ }^{+\ldots} \mathrm{Cl}^{-}$ion pair state at the minimum is its proximity to the next low-lying ${ }^{1} A_{1}\left(n_{\sigma} 2 p_{\sigma}\right)$ state, which at the level used for optimization (MR-CISD/valence/B1) is only $-0.1 \mathrm{eV}$. Thus, the $\mathrm{CF}_{3}{ }^{+} \mathrm{Cl}^{-}$ion pair state effectively becomes the ground state of the pre-dissociated species but closely 
followed by the $n_{\sigma} 2 p_{\sigma}$ state. Naturally, we expect to find a conical intersection between these states nearby.

A minimum-energy conical intersection was optimized between the $2^{1} \mathrm{~A}_{1}$ and $1{ }^{1} \mathrm{~A}_{1}$ states. The structure of this conical intersection is virtually identical to that of the ion-pair minimum (see Figure 5). It lies $5.20 \mathrm{eV}$ above the optimized structure of the ground state (MR-CISD $+\mathrm{Q} /$ valence/aug-cc-pVTZ level). Computed at the same level, the ion-pair minimum is at $4.98 \mathrm{eV}$, therefore, $0.22 \mathrm{eV}$ below the intersection.

In Table 5, one has the vertical excitation energies, oscillator strengths $(f)$, and the main configurations for the nearby electronic states at the minimum and conical intersection structures. As can be seen from this table at both structures, the states are very close at the MR-CISD level, with a maximum difference of $0.17 \mathrm{eV}$ for the $1{ }^{1} \mathrm{E}$ state at the structure of the ion-pair minimum. Upon inclusion of size-extensivity correction (MR-CISD+Q), all differences increase, with a maximum value of $0.36 \mathrm{eV}$. Moreover, the states' ordering change at this latter level, such that the ion-pair minimum and the conical intersection become the lowest states at their own structures. As the ion-pair minimum and the conical intersection structures have very similar geometries, Table 5 indicates that subtle geometric changes in the ion-pair structure greatly enhance the coupling between the $\left(2 \mathrm{p}_{\sigma}\right)^{1}\left(\mathrm{n}_{\sigma}(\mathrm{Cl})\right)^{1}$ and the ionic configurations.

Table 5. Vertical excitation energies (in $\mathrm{eV}$ ), oscillator strengths $(f)$ and main configurations for the nearby electronic states in the minimum and in the conical intersection structures. Values have been computed with the valence space along with the aug-cc-pVTZ basis set and are relative to the ground state minimum.

\begin{tabular}{llllll}
\hline State & $\Delta E(\mathrm{eV})$ & \multicolumn{2}{l}{} & nearby state $^{\mathrm{a}}$ & main configuration \\
\cline { 2 - 4 } & $\mathrm{CI}^{\mathrm{b}}$ & $\mathrm{CI}+\mathrm{Q}^{\mathrm{c}}$ & & & \\
\hline ion-pair & 5.35 & 4.98 & --- & --- & 0.67 ionic $+0.18\left(2 \mathrm{p}_{\sigma}\right)^{1}\left(\mathrm{n}_{\sigma}(\mathrm{Cl})\right)^{1}$ \\
minimum & 5.25 & 5.30 & 0.011 & $1^{1} \mathrm{~A}_{1}$ & $0.68\left(2 \mathrm{p}_{\sigma}\right)^{1}\left(\mathrm{n}_{\sigma}(\mathrm{Cl})\right)^{1}+0.18$ ionic \\
& 5.18 & 5.34 & $<10^{-6}$ & $1^{1} \mathrm{E}$ & $0.86 \mathrm{n}_{\mathrm{e}} 2 \mathrm{p}_{\sigma}$ \\
conical & 5.35 & 5.20 & ---- & ---- & $0.78\left(2 \mathrm{p}_{\sigma}\right)^{1}\left(\mathrm{n}_{\sigma}(\mathrm{Cl})\right)^{1} / 0.77$ ionic $^{\mathrm{d}}$ \\
intersection & & & & & \\
& 5.26 & 5.43 & $6 \times 10^{-6}$ & $1^{1} \mathrm{E}$ & $0.86 \mathrm{n}_{\mathrm{e}} 2 \mathrm{p}_{\sigma}$ \\
\hline
\end{tabular}

${ }^{\mathrm{a}}$ The distinction between $1{ }^{1} \mathrm{~A}_{1}$ and $2{ }^{1} \mathrm{~A}_{1}$ states is based on their CI energies; ${ }^{\mathrm{b}} \mathrm{MR}-\mathrm{CISD} ;{ }^{\mathrm{c}} \mathrm{MR}-\mathrm{CISD}+\mathrm{Q} ;{ }^{\mathrm{d}}$ Pair of degenerate states $\left(1^{1} \mathrm{~A}_{1} / 2^{1} \mathrm{~A}_{1}\right)$ characterizing the conical intersection. 
As can also be seen from Table 5, the $f$ values are almost negligible for transitions involving the $1^{1} \mathrm{E}$ state, at both structures. At the ion-pair structure the $f$ value corresponding to the ion-pair $\rightarrow 1^{1} \mathrm{~A}_{1}$ transition is very similar to that of the ground state $\rightarrow 1^{1} \mathrm{E}\left(\mathrm{n} \sigma^{*}\right)$ (see Table 2). However, the former transition is in the infrared region and can thus take place by IR absorption and, if it does, it can either lead to the neutral ground state fragments or to the ground state minimum. As discussed below, conversion from the ion-pair to the conical intersection can also lead to the same products.

In Figure 6 (a), the branching space vectors $\mathbf{g}$ (gradient difference) and $\mathbf{h}$ (nonadiabatic coupling) are shown. The gradient difference combines $\mathrm{CF}_{3}$ breathing with the $\mathrm{C}-\mathrm{Cl}$ bond stretching, while the nonadiabatic coupling vector is dominated by the umbrella mode. The double cone around the $2{ }^{1} \mathrm{~A}_{1} / 1^{1} \mathrm{~A}_{1}$ intersection is shown in Figure $6(\mathrm{~b})$.

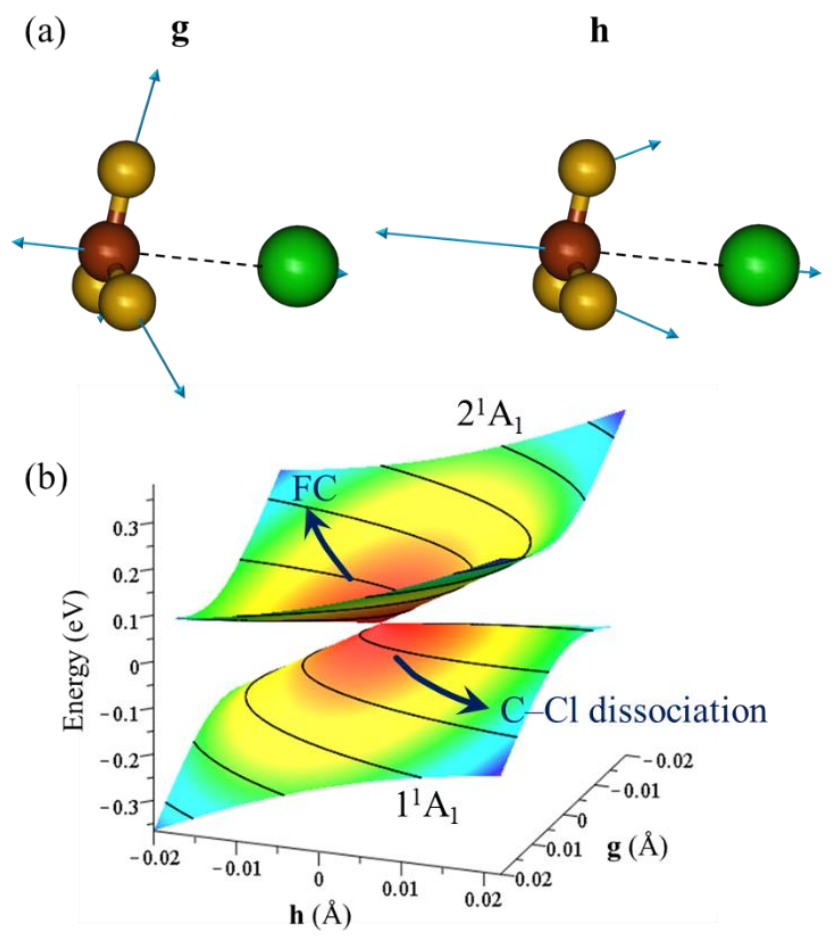

Figure 6. (a) Normalized branching space vectors $\mathbf{g}$ (gradient difference) and $\mathbf{h}$ (nonadiabatic coupling) obtained for the conical intersection between the $2{ }^{1} \mathrm{~A}_{1}$ and $1{ }^{1} \mathrm{~A}_{1}$ states. (b) Double cone plot characterizing this conical intersection. The arrows in (b) indicate the directions to the Franck-Condon (FC) region and $\mathrm{C}-\mathrm{Cl}$ dissociation. 
Internal conversion from the ion pair to the ground state at the $2{ }^{1} \mathrm{~A}_{1} / 1{ }^{1} \mathrm{~A}_{1}$ conical intersection implies an electron transfer because the fragments in the ground state are neutral. This transfer should, in principle, reduce the efficiency of the intersection, keeping the molecule diabatically trapped in the ion-pair state. Note, however, that starting from the intersection, the directions with positive and negative $\mathbf{h}$ keeping $\mathbf{g}=0$ is flat due to the existence of the ion-pair minimum closely below the intersection. Therefore, the wave packet sitting at the ion-pair minimum should continuously experience nonadiabatic interactions, which should act against the diabatic trapping, rendering an ultrashort lifetime for the $\mathrm{CF}_{3}{ }^{+\ldots} \mathrm{Cl}^{-}$ion pair.

After the internal conversion, $\mathrm{CF}_{3} \mathrm{Cl}$ may be recovered or dissociate into neutral fragments. The double cone is nearly symmetrical in the g direction and strongly tilted in the $\mathbf{h}$ direction, sharply stabilizing the $1{ }^{1} \mathrm{~A}_{1}$ energy along negative $\mathbf{h}$. This topographical feature creates a bias towards recovering $\mathrm{CF}_{3} \mathrm{Cl}$. Nevertheless, the final dissociation yield also depends on the nuclear momentum and this information is not available in the present work.

The $1 \mathrm{~A}_{1} / 2 \mathrm{~A}_{1}$ conical intersection marks a sharp distinction between $\mathrm{CF}_{3}{ }^{+}{ }^{+\ldots} \mathrm{Cl}^{-}$and $\mathrm{CH}_{3}{ }^{+} \ldots \mathrm{Cl}^{-}$ion pairs. In the latter, there is no low-lying conical intersection, and the pair reorganizes as $\mathrm{H}_{2} \mathrm{CH}^{+\cdots} \mathrm{Cl}^{-}$forming a $\mathrm{CH}^{\cdots} \mathrm{Cl}$ hydrogen bond. ${ }^{18}$

As discussed in the Introduction, the appearance of $\mathrm{Cl}^{-}$in the dissociation of $\mathrm{CF}_{3} \mathrm{Cl}$ only occurs for excitations above $16.1 \mathrm{eV},{ }^{13}$ although the ion-pair dissociation channel lies much lower, at $8.99 \mathrm{eV}$ (MR-CISD+Q, Table 4). Our results can directly rationalize this fact. The $2{ }^{1} \mathrm{~A}_{1}$ is the only low-energy state that could lead to the formation of $\mathrm{Cl}^{-}\left(\right.$and $\mathrm{CF}_{3}{ }^{+}$). Because it can easily form a conical intersection with the $1{ }^{1} \mathrm{~A}_{1}$ state, this state nonadiabatically deactivates in the region of the ion pair, either yielding the neutral $\mathrm{CF}_{3}$ and $\mathrm{Cl}$ fragments in their respective ground states through the dissociation channel (1) or regenerating the ground state of $\mathrm{CF}_{3} \mathrm{Cl}$. Simpson et al. ${ }^{13}$ showed that the same anomalous photochemistry is observed in $\mathrm{CF}_{3} \mathrm{Br}$ and $\mathrm{CF}_{3} \mathrm{I}$ whose $\mathrm{Br}^{-}$and $\mathrm{I}^{-}$signals at low energies are much weaker than expected. It is clear now that these other species should have the same kind of conical intersection between their lowest ion-pair state and the ground state. 


\subsection{Fluorescence of $\mathrm{CF}_{3} \mathrm{Cl}$}

Fluorescence of $\mathrm{CF}_{3} \mathrm{Cl}$ has been measured after excitation in the range from 8 to $22 \mathrm{eV} .^{10,14}$ The total fluorescence has an onset about $10 \mathrm{eV},{ }^{14}$ with peaks at 11.29 and $15.90 \mathrm{eV}$, and shoulders at 10.9 and $13.2 \mathrm{eV}$. For excitation at about $11 \mathrm{eV}$, the emission shows two broad bands, one in the UV at 5-5.6 eV and another in the visible around 2-2.25 eV. ${ }^{8}$ All these emission features have been assigned to $\mathrm{CF}_{3} *$ emission. In this section, we discuss the reason why $\mathrm{CF}_{3} \mathrm{Cl}$ does not fluoresce.

The potential energy profiles along the $\mathrm{C}-\mathrm{Cl}$ bond suggest the occurrence of several candidates for excited states minima in the $2^{1} \mathrm{E}, 5^{1} \mathrm{~A}_{1}, 5^{1} \mathrm{E}, 4^{1} \mathrm{~A}_{1}$, and $3{ }^{1} \mathrm{~A}_{1}$ states (Figure 2). Nevertheless, only in the case of the $2^{1} \mathrm{E}$ state, a minimum has been obtained (cf. Section 3.3). During the geometry optimizations of the remaining states at the MR-CIS level under $\mathrm{C}_{\mathrm{s}}$ symmetry $\left(10^{1} \mathrm{~A}^{\prime}\right.$ from $5^{1} \mathrm{~A}_{1} ; 9^{1} \mathrm{~A}^{\prime}$ or $6^{1} \mathrm{~A}^{\prime \prime}$ from $5^{1} \mathrm{E} ; 7^{1} \mathrm{~A}^{\prime}$ from $3^{1} \mathrm{~A}_{1}$, and $7^{1} \mathrm{~A}^{\prime}$ from $4^{1} \mathrm{~A}_{1}$ ) nearly triply-degenerate states have been obtained, thus preventing completion of the geometry optimizations. These near-degeneracies between multiple states suggests the existence of multiple-state conical intersections, ${ }^{50}$ which can deactivate the excited states through a cascade of nonadiabatic processes, eventually bringing the molecule to the ion-pair state $2^{1} \mathrm{~A}_{1}$. If this state is populated, another conical intersection (discussed in Section 3.7) can bring the system to the ground state, eliminating any possibility of photoemission.

Thus, if any fluorescence from $\mathrm{CF}_{3} \mathrm{Cl}$ emission can occur, it should happen only for excitation near the origin of the $\mathrm{n}_{\mathrm{e}} 4 \mathrm{~s}$ state $(9.16 \mathrm{eV} ; 135 \mathrm{~nm})$, as any higher value would enhance the internal conversion (and tunneling) to the $2{ }^{1} \mathrm{~A}_{1}$ state. Thus, after exciting the $\mathrm{n}_{\mathrm{e}} 4 \mathrm{~s}$ band origin, this state could irradiate and relax either to the $1^{1} \mathrm{E}$ or $1^{1} \mathrm{~A}_{1}$ states. If the target state is the $1^{1} \mathrm{E}$, the emission lies in the visible, with an energy difference of $2.83 \mathrm{eV}(438$ $\mathrm{nm}$ ) calculated at the MR-CISD+Q/refl level. If the target state is the $1{ }^{1} \mathrm{~A}_{1}$, the emission is in the far UV, with $8.61 \mathrm{eV}(144 \mathrm{~nm})$ at the same level. These two transitions are schematically depicted in Figure 2. Although the oscillator strength values given in Table 3 indicate that both are allowed transitions (especially the UV emission), the computed radiative lifetimes yield values of $1.3 \mu \mathrm{s}$ and $5.6 \mathrm{~ns}$ for the visible and UV emissions, respectively. Therefore, due to the much longer radiative lifetime for the visible emission, 
the $n_{e} 4 s$ state excited in the band origin would likely either emit in the UV or tunnel to $2{ }^{1} \mathrm{~A}_{1}$ before any possibility of visible emission.

\section{CONCLUSIONS}

For the first time, high-level electronic structure calculations at the MR-CISD+Q level have been performed to study the potential energy curves of valence and Rydberg states of $\mathrm{CF}_{3} \mathrm{Cl}$ along the $\mathrm{C}-\mathrm{Cl}$ coordinate. They allowed a comprehensive interpretation and assignment of experimental data concerning fluorescence, deactivation of the ion pair, and generation of $\mathrm{CF}_{3}$ fragment in several electronic states.

States converging to the five lowest dissociation channels were investigated. None of these channels leads to the formation of excited $\mathrm{Cl}$ atom, although most of the initial FranckCondon excitations are located at the $\mathrm{Cl}$ atom. These channels, however, can produce $\mathrm{CF}_{3}$ radical either in the ground (channel (1)) or in different excited states (channels (3)-(5)). Channel (2), in turn, leads to a $\mathrm{CF}_{3}{ }^{+} \ldots \mathrm{Cl}^{-}$ion-pair production.

The topography of the lowest states is schematically illustrated in Figure 7. This qualitative picture collects some of the major features revealed by the calculations.

The $n_{e} 4 p_{e}$ state, which becomes the ion-pair state (ionic), plays a critical role in $\mathrm{CF}_{3} \mathrm{Cl}$ dissociation. Due to the strong Coulomb interaction between $\mathrm{CF}_{3}{ }^{+}$and $\mathrm{Cl}^{-}$, it stabilizes up to become nearly degenerated with the $\sigma \sigma^{*}$ state, where it has a minimum (Section 3.7). During this stabilization, it also crosses the $n_{e} 4 s$ and the $n_{e} \sigma^{*}$ states. The dissociation energy of this state, corresponding to the channel (2), is the third in energy (Table 4), which means that the ion-pair state re-cross all those states again on its way to dissociation.

The $n_{e} 4 s$ state also features a minimum (Section 3.3), and it dissociates along the channel (3) (the second in energy, Table 4). Curiously, the dissociation energy is below the energy of the minimum, meaning that they are separated by a barrier. This barrier is caused by interactions with the $n_{\mathrm{e}} 3 \mathrm{~s}$ state, which also dissociates along the channel (3). 


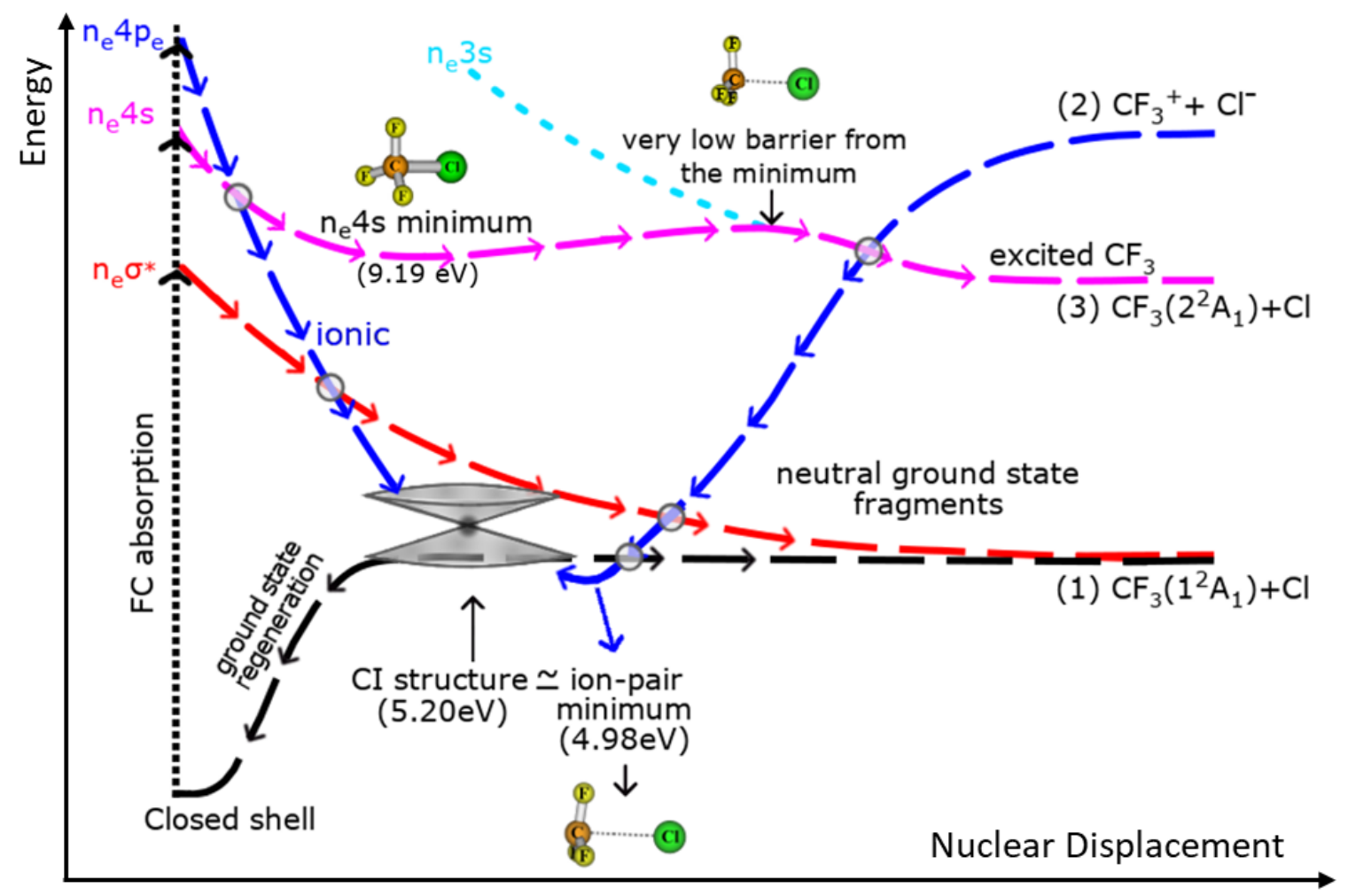

Figure 7. Schematic picture of the $\mathrm{CF}_{3} \mathrm{Cl}$ dissociation in the low-lying excited states. From each crossing, the system can follow two new pathways. From the conical intersection (CI), ground state regeneration or generation of the neutral ground state fragments can take place. The values given do not include zero-point corrections and have been obtained at the MR-CISD+Q level with the ref 2 space for the $\mathrm{n}_{\mathrm{e}} 4 \mathrm{~s}$ state and with the valence space for the remaining structures.

Experimentally, $\mathrm{CF}_{3} \mathrm{Cl}$ is known for its anomalous photolysis, which does not produce $\mathrm{Cl}^{-}$even though it is energetically allowed. ${ }^{12-13}$ The present results explain this phenomenon. The $\mathrm{CF}_{3}{ }^{+} \ldots \mathrm{Cl}^{-}$ion pair minimum is in the vicinity of a conical intersection with the ground state (ionic in Figure 7). At this intersection, $\mathrm{CF}_{3} \mathrm{Cl}$ either returns to the ground state or dissociates into neutral fragments. This analysis should help rationalize why other halogenfluorocarbons like $\mathrm{CF}_{3} \mathrm{Br}$ and $\mathrm{CF}_{3} \mathrm{I}$ analogously exhibit weak anion signals.

The excited-state energy profile shows several easily accessible state intersections connecting states up to the fourth absorption band. In particular, the existence of multiplestate intersections, in two geometrical spots at $\mathrm{C}-\mathrm{Cl}$ distances of $\sim 1.7$ and $3.0 \AA$, can promote several nonadiabatic events, bringing the molecule to lower excited states or driving it to 
dissociation. This relaxation pattern precludes any relaxation to an excited-state minimum from where it could fluoresce. The only possible photoemission would arise from excitation into the band origin of the $n_{e} 4 s$ state, from where radiative decay to $1{ }^{1} \mathrm{~A}_{1}$ would result in farUV emission at $144 \mathrm{~nm}$.

Excited-state photodissociation is still an outstanding challenge for computational theoretical chemistry. As we have seen, even its description for a small molecule like $\mathrm{CF}_{3} \mathrm{Cl}$ requires pushing high-level multireference methods to their limits. The construction of active and multireference spaces composed of semi-independent subspaces, as done here, sets an optimal strategy, which we hope will guide future works in this field.

\section{ASSOCIATED CONTENT}

\section{Supporting Information}

The Supporting Information is available free of charge on the ACS Publications website. Cartesian coordinates; information about the absorption spectrum (PDF)

\section{AUTHOR INFORMATION}

\section{Corresponding authors}

* E-mail: mario.barbatti@univ-amu.fr; website: www.barbatti.org

* E-mail: silmar@quimica.ufpb.br or silmar.monte@uol.com.br

\section{ORCID}

Vanessa C. de Medeiros: 0000-0003-0829-945X

Railton B. de Andrade: 0000-0001-5804-4186

Gessenildo P. Rodrigues: 0000-0002-1166-9231

Glauco F. Bauerfeldt: 0000-0001-5906-7080

Elizete Ventura: 0000-0002-1015-7824

Mario Barbatti: 0000-0001-9336-6607 
Silmar A. do Monte: 0000-0002-5878-1984

\section{Funding}

M.B. thanks the support of the Excellence Initiative of Aix-Marseille University (A*MIDEX) and the project Equip@Meso (ANR-10-EQPX-29-01), both funded by the French Government "Investissements d'Avenir" program m. M.B. also acknowledges funding the WSPLIT project (ANR-17-CE05-0005-01). The remaining authors are grateful to the Brazilian agencies CNPq (Grant number 309785/2015-4), CAPES, and FINEP for financial support.

\section{Notes}

The authors declare no competing financial interest.

\section{REFERENCES}

(1) Seinfeld, J. H.; Pandis, S. N., Atmospheric Chemistry and Physics: From Air Pollution to Climate Change, . 3rd ed.; Willey: 2016; p 119.

(2) Montreal Protocol on Substances that Deplete the Ozone Layer. http://ozone.unep.org/ (accessed May 9, 2018).

(3) Montzka, S. A., Source Gases that Affect Stratospheric Ozone. In Stratospheric Ozone Depletion and Climate Change, The Royal Society of Chemistry: 2012; pp 33-77.

(4) Montzka, S. A.; Dutton, G. S.; Yu, P.; Ray, E.; Portmann, R. W.; Daniel, J. S.; Kuijpers, L.; Hall, B. D.; Mondeel, D.; Siso, C., et al. An unexpected and persistent increase in global emissions of ozone-depleting CFC-11. Nature 2018, 557, 413-417.

(5) Molina, M. J.; Rowland, F. S. Stratospheric Sink for Chlorofluoromethanes: Chlorine Atom-Catalysed Destruction of Ozone. Nature 1974, 249, 810-812.

(6) Rowland, F. S.; Molina, M. J. Chlorofluoromethanes in the environment. Rev. Geophys. 1975, 13, 1-35.

(7) Okabe, H., Photochemistry of Small Molecules. John Wiley \& Sons: New York, 1978; p 350 . 
(8) Suto, M.; Washida, N.; Akimoto, H.; Nakamura, M. Emission Spectra of $\mathrm{CF}_{3}$ Radicals. III. Spectra and Quenching of $\mathrm{CF}_{3}$ Emission Bands Produced in the VUV Photolyses of $\mathrm{CF}_{3} \mathrm{Cl}$ and $\mathrm{CF}_{3} \mathrm{Br}$. J. Chem. Phys. 1983, 78, 1019-1024.

(9) Washida, N.; Suto, M.; Nagase, S.; Nagashima, U.; Morokuma, K. Emission Spectra of $\mathrm{CF}_{3}$ Radicals. IV. Excitation Spectra, Quantum Yields, and Potential Energy Surfaces of the $\mathrm{CF}_{3}$ Fluorescences. J. Chem. Phys. 1983, 78, 1025-1032.

(10) Suto, M.; Lee, L. C. Emission Spectra of $\mathrm{CF}_{3}$ Radicals. V. Photodissociation of $\mathrm{CF}_{3} \mathrm{H}$, $\mathrm{CF}_{3} \mathrm{Cl}$, and $\mathrm{CF}_{3} \mathrm{Br}$ by Vacuum Ultraviolet. J. Chem. Phys. 1983, 79, 1127-1133.

(11) Yen, M. w.; Johnson, P. M.; White, M. G. The vacuum ultraviolet photodissociation of the chlorofluorocarbons. Photolysis of $\mathrm{CF}_{3} \mathrm{Cl}, \mathrm{CF}_{2} \mathrm{Cl}_{2}$, and $\mathrm{CFCl}_{3}$ at 187,125 , and $118 \mathrm{~nm}$. J. Chem. Phys. 1993, 99, 126-139.

(12) Schenk, H.; Oertel, H.; Baumgärtel, H. Photoreactions of Small Organic Molecules VII Photoionization Studies on the Ion-Pair Formation of the Fluorochloromethanes $\mathrm{CF}_{2} \mathrm{Cl}_{2}$, $\mathrm{CF}_{3} \mathrm{Cl}$, and $\mathrm{CFCl}_{3}$. Berichte der Bunsengesellschaft für physikalische Chemie 1979, 83, 683691.

(13) Simpson, M. J.; Tuckett, R. P.; Dunn, K. F.; Hunniford, C. A.; Latimer, C. J. VacuumUV negative photoion spectroscopy of $\mathrm{CF}_{3} \mathrm{Cl}, \mathrm{CF}_{3} \mathrm{Br}$, and $\mathrm{CF}_{3} \mathrm{I}$. J. Chem. Phys. 2009, 130, 194302.

(14) Ali, S. Gas Phase Vacuum-Ultraviolet (VUV) Spectroscopy of Small Hallogenated Polyatomic Molecules. The University of Birmingham, Birmingham, 2007.

(15) Stojanović, L.; Alyoubi, A. O.; Aziz, S. G.; Hilal, R. H.; Barbatti, M. UV Excitations of Halons. J. Chem. Phys. 2016, 145, 184306.

(16) de Medeiros, V. C.; do Monte, S. A.; Ventura, E.; de Andrade, R. B.; Bauerfeld, G. F. Mol. Phys. 2018, DOI:10.1080/00268976.2018.1467050.

(17) de Medeiros, V. C.; do Monte, S. A.; Ventura, E. Valence and Rydberg states of $\mathrm{CH}_{3} \mathrm{Cl}$ : a MR-CISD study. RSC Advances 2014, 4, 64085-64092.

(18) de Medeiros, V. C.; de Andrade, R. B.; Leitão, E. F. V.; Ventura, E.; Bauerfeldt, G. F.; Barbatti, M.; do Monte, S. A. Photochemistry of $\mathrm{CH}_{3} \mathrm{Cl}$ : Dissociation and $\mathrm{CH} \cdots \mathrm{Cl}$ Hydrogen Bond Formation. J. Am. Chem. Soc. 2016, 138, 272-280.

(19) De Medeiros, V. C.; Ventura, E.; do Monte, S. A. CASSCF and MR-CISD Study of the $\mathrm{n}-4 \mathrm{~s}$ and n-4pe Rydberg States of the $\mathrm{CF}_{3} \mathrm{Cl}$. Chem. Phys. Lett. 2012, 546, 30-33. 
(20) Lucena Jr., J. R.; Ventura, E.; do Monte, S. A.; Araújo, R. C. M. U.; Ramos, M. N.; Fausto, R. Dissociation of Ground and n $\sigma^{*}$ States of $\mathrm{CF}_{3} \mathrm{Cl}$ Using Multireference Configuration Interaction with Singles and Doubles and with Multireference Average Quadratic Coupled Cluster Extensivity Corrections. J. Chem. Phys. 2007, 127, 164320.

(21) Langhoff, S. R.; Davidson, E. R. Configuration Interaction Calculations on Nitrogen Molecule. Int. J. Quantum Chem. 1974, 8, 61-72.

(22) Bruna, P. J.; Peyerimhoff, S. D.; Buenker, R. J. The Ground-State of the Cn+ Ion - a Multi-Reference Ci Study. Chem. Phys. Lett. 1980, 72, 278-284.

(23) Dunning Jr, T. H. Gaussian-Basis Sets for Use in Correlated Molecular Calculations .1. The Atoms Boron through Neon and Hydrogen. J. Chem. Phys. 1989, 90, 1007-1023.

(24) Woon, D. E.; Jr., T. H. D. Gaussian basis sets for use in correlated molecular calculations. III. The atoms aluminum through argon. J. Chem. Phys. 1993, 98, 1358-1371.

(25) Kendall, R. A.; Dunning Jr., T. H.; Harrison, R. J. Electron affinities of the first-row atoms revisited. Systematic basis sets and wave functions. J. Chem. Phys. 1992, 96, 12.

(26) Woon, D. E.; Dunning Jr., T. H. Gaussian Basis Sets for Use in Correlated Molecular Calculations. IV. Calculation of Static Electrical Response Properties. J. Chem. Phys. 1994, 100, 2975-2988.

(27) Shepard, R. Geometrical energy derivative evaluation with MRCI wave functions. Int. J. Quantum Chem. 1987, 31, 33-44.

(28) Shepard, R.; Lischka, H.; Szalay, P. G.; Kovar, T.; Ernzerhof, M. A General Multireference Configuration-Interaction Gradient Program. J. Chem. Phys. 1992, 96, 20852098.

(29) Shepard, R., The Analytic Gradient Method for Configuration Interaction Wave Functions. In Modern Electronic Structure Theory, Yarkony, D. R., Ed. World Scientific: Singapore, 1995; Vol. 1, p 345.

(30) Lischka, H.; Dallos, M.; Shepard, R. Analytic MRCI Gradient for Excited States: Formalism and Application to the $n-\pi^{*}$ Valence- and $n-(3 s, 3 p)$ Rydberg States of Formaldehyde. Mol. Phys. 2002, 100, 1647-1658. 
(31) Lischka, H.; Dallos, M.; Szalay, P. G.; Yarkony, D. R.; Shepard, R. Analytic Evaluation of Nonadiabatic Coupling Terms at the MR-CI Level. I. Formalism. J. Chem. Phys. 2004, 120, 7322-7329.

(32) Dallos, M.; Lischka, H.; Shepard, R.; Yarkony, D. R.; Szalay, P. G. Analytic Evaluation of Nonadiabatic Coupling Terms at the MR-CI Level. II. Minima on the Crossing Seam: Formaldehyde and the Photodimerization of Ethylene. J. Chem. Phys. 2004, 120, 7330-7339.

(33) Szalay, P. G.; Bartlett, R. J. Multi-reference averaged quadratic coupled-cluster method: a size-extensive modification of multi-reference CI. Chem. Phys. Lett. 1993, 214 , 481-488.

(34) Szalay, P. G.; Bartlett, R. J. Approximately extensive modifications of the multireference configuration interaction method: A theoretical and practical analysis. $J$. Chem. Phys. 1995, 103, 3600-3612.

(35) Bunge, A. Electronic Wavefunctions for Atoms .3. Partition of Degenerate Spaces and Ground State of C. J. Chem. Phys. 1970, 53, 20-28.

(36) Lischka, H.; Shepard, R.; Brown, F. B.; Shavitt, I. New Implementation of the Graphical Unitary-Group Approach for Multi-Reference Direct Configuration-Interaction Calculations. Int. J. Quantum Chem. 1981, 20, 91-100.

(37) Shepard, R.; Shavitt, I.; Pitzer, R. M.; Comeau, D. C.; Pepper, M.; Lischka, H.; Szalay, P. G.; Ahlrichs, R.; Brown, F. B.; Zhao, J. A Progress Report on the Status of the COLUMBUS MRCI Program System. Int. J. Quantum Chem. 1988, 34, 149-165.

(38) Lischka, H.; Shepard, R.; Shavitt, I.; Pitzer, R. M.; Dallos, M.; Müller, T.; Szalay, P. G.; Brown, F. B.; Ahlrichs, R.; Böhm, H. J., et al. COLUMBUS, an ab initio electronic structure program, release 7.0. www.univie.ac.at/columbus (accessed May 9, 2018).

(39) Lischka, H.; Shepard, R.; Pitzer, R. M.; Shavitt, I.; Dallos, M.; Müller, T.; Szalay, P. G.; Seth, M.; Kedziora, G. S.; Yabushita, S., et al. New High-Level Multireference Methods in the Quantum-Chemistry Program System COLUMBUS: Analytic MR-CISD and MRAQCC Gradients and MR-AQCC-LRT for Excited States, GUGA Spin-Orbit CI, and Parallel CI Density. Phys. Chem. Chem. Phys. 2001, 3, 664-673. 
(40) Helgaker, T.; Jensen, H. J. A.; Jørgensen, P.; Olsen, J.; Ruud, K.; Ågren, H.; Andersen, T.; Bak, K. L.; V. Bakken; Christiansen, O., et al. DALTON, an ab initio electronic structure program, Release 1.01997.

(41) Au, J. W.; Burton, G. R.; Brion, C. E. Quantitative spectroscopic studies of the valence-shell electronic excitation of freons $\left(\mathrm{CFCl}_{3}, \mathrm{CF}_{2} \mathrm{Cl}_{2}, \mathrm{CF}_{3} \mathrm{Cl}\right.$, and $\left.\mathrm{CF}_{4}\right)$ in the $\mathrm{VUV}$ and soft X-ray regions. Chem. Phys. 1997, 221, 151-168.

(42) Eden, S.; Limão-Vieira, P.; Hoffmann, S. V.; Mason, N. J. VUV Photoabsorption in $\mathrm{CF}_{3} \mathrm{X}(\mathrm{X}=\mathrm{Cl}, \mathrm{Br}, \mathrm{I})$ Fluoro-alkanes. Chem. Phys. 2006, 323, 313-333.

(43) Ying, J. F.; Mathers, C. P.; Leung, K. T.; Pritchard, H. P.; Winstead, C.; McKoy, V. Observation of a "new" quadrupole transition at $7.7 \mathrm{eV}$ in $\mathrm{CF}_{3} \mathrm{Cl}$ by momentum-transferresolved electron energy loss spectroscopy. Chem. Phys. Lett. 1993, 212, 289-297.

(44) Avila Ferrer, F. J.; Cerezo, J.; Stendardo, E.; Improta, R.; Santoro, F. Insights for an Accurate Comparison of Computational Data to Experimental Absorption and Emission Spectra: Beyond the Vertical Transition Approximation. J. Chem. Theory Comput. 2013, 9, 2072-2082.

(45) Wu, W.; Zhang, H.; Braïda, B.; Shaik, S.; Hiberty, P. The V State of Ethylene: Valence Bond Theory Takes up the Challenge. Theor. Chem. Acc. 2014, 133, 1-13.

(46) Angeli, C. On the Nature of the $\pi \rightarrow \pi^{*}$ Ionic Excited States: The V State of Ethene as a Prototype. J. Comput. Chem. 2009, 30, 1319-1333.

(47) Pitarch-Ruiz, J.; Sánchez de Merás, A.; Sánchez-Marín, J.; Mayor, E.; Velasco, A. M.; Martín, I. Excitation Energies and Photoabsorption Oscillator Strengths of the Rydberg Series in CF3Cl. A Linear Response and Quantum Defect Study. J. Phys. Chem. A 2007, 111, 33213325.

(48) Johnson III, R. D. NIST Standard Reference Database Number 101 Release 16a, August 2013. http://cccbdb.nist.gov/ (accessed April 12, 2018).

(49) Dossmann, H.; Garcia, G. A.; Nahon, L.; Miranda, B. K. C. d.; Alcaraz, C. Comprehensive vacuum ultraviolet photoionization study of the CF3 • trifluoromethyl radical using synchrotron radiation. J. Chem. Phys. 2012, 136, 204304.

(50) Matsika, S.; Yarkony, D. R. Beyond Two-State Conical Intersections. Three-State Conical Intersections in Low Symmetry Molecules: the Allyl Radical. J. Am. Chem. Soc. 2003, 125, 10672-10676. 


\section{FOR TABLE OF CONTENTS ONLY}

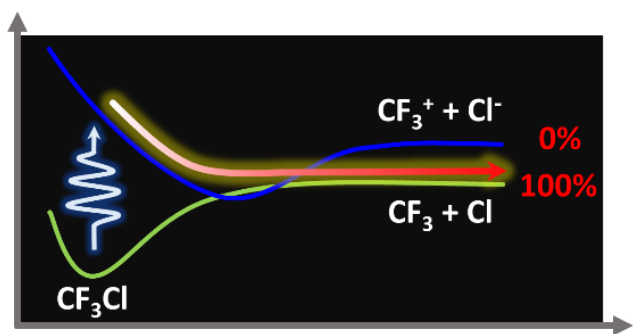

de Medeiros et al., Photochemistry of $\mathrm{CF}_{3} \mathrm{Cl}$ (2018) 